\title{
Targeted reforestation could reverse declines in connectivity for understory birds in a tropical habitat corridor
}

\author{
Matthew E. Fagan, ${ }^{1,6}$ Ruth S. DeFries, ${ }^{2}$ Steven E. Sesnie, ${ }^{3}$ J. Pablo Arroyo-Mora,,${ }^{4}$ and Robin L. Chazdon 5 \\ ${ }^{1}$ Biospheric Sciences, Goddard Space Flight Center, NASA, Greenbelt, Maryland 20771 USA \\ ${ }^{2}$ Department of Ecology, Evolution, and Environmental Biology, Columbia University, 10th Floor Schermerhorn Extension, \\ New York, New York 10027 USA \\ ${ }^{3}$ U.S. Fish and Wildlife Service, P.O. Box 1306, Albuquerque, New Mexico 87103 USA \\ ${ }^{4}$ Department of Geography, McGill University, 805 Sherbrooke Street, West Montreal, Quebec H3 A2K6 Canada \\ ${ }^{5}$ Department of Ecology and Evolutionary Biology, University of Connecticut, U-3043 75 North Eagleville Road, Storrs, \\ Connecticut 06269-3043 USA
}

\begin{abstract}
Re-establishing connectivity between protected areas isolated by habitat clearing is a key conservation goal in the humid tropics. In northeastern Costa Rica, payments for environmental services (PES) and a government ban on deforestation have subsidized forest protection and reforestation in the San Juan-La Selva Biological Corridor (SJLSBC), resulting in a decline in mature forest loss and the expansion of tree plantations. We use field studies and graph models to assess how conservation efforts have altered functional connectivity over the last 25 years for four species of insectivorous understory birds. Field playback studies assessed how reforestation habitat quality affected the willingness of Myrmeciza exsul, Henicorhina leucosticta, Thamnophilus atrinucha, and Glyphorynchus spirurus to travel outside forest habitat for territorial defense. Observed travel distances were greatest in nonnative and native tree plantations with high understory stem density, regardless of overstory composition. In contrast, tree plantations with low stem density had travel responses comparable to open pasture for three of the four bird species. We modeled landscape connectivity for each species using graph models based on varying possible travel distances in tree plantations, gallery forests, and pastures. From 1986 to 2011, connectivity for all species declined in the SJLSBC landscape $\left(5825 \mathrm{~km}^{2}\right)$ by $14 \%$ to $21 \%$ despite only a $4.9 \%$ net loss in forest area and the rapid expansion of tree plantations over $2 \%$ of the landscape. Plantation placement in the landscape limited their potential facilitation of connectivity because they were located either far from forest cover or within already contiguous forest areas. We mapped current connectivity bottlenecks and identified priority areas for future reforestation. We estimate that reforestation of priority areas could improve connectivity by $2 \%$ with only a $1 \%$ gain in forest cover, an impressive gain given the small area reforested. Results indicate key locations where spatial targeting of PES within the SJLSBC study region would protect existing forest connectivity and enhance the connectivity benefits of reforestation.
\end{abstract}

Key words: Costa Rica; fragmentation; functional connectivity; Glyphorynchus spirurus; Henicorhina leucosticta; Myrmeciza exsul; payments for environmental services; reforestation; Thamnophilus atrinucha; tropical conservation; understory insectivores.

\section{INTRODUCTION}

The ongoing conversion of humid tropical forests to agricultural lands in Latin America, Africa, and Southeast Asia is a major threat to global biodiversity (Sekercioglu and Sodhi 2007, Stork et al. 2009, Gibbs et al. 2010). Isolation of remaining tropical forest patches in landscapes dominated by agricultural land use causes further species extinctions, as forest fragments undergo

Manuscript received 18 November 2014; revised 20 October 2015; accepted 5 November 2015. Corresponding Editor: J. M. Marzluff.

${ }^{6}$ Present address: Department of Geography and Environmental Systems, University of Maryland, Baltimore County, 1000 Hilltop Circle, Baltimore, Maryland 21250 USA. E-mail: mfagan@umbc. edu "faunal relaxation" over several decades (Brooks et al. 1999, Ferraz et al. 2003). Populations of species that are not connected to other populations through the interchange of individuals can undergo a loss of genetic diversity and are more likely to suffer local extinction (Saccheri et al. 1998, Cushman et al. 2006). Maintaining functionally connected populations between persisting fragments of humid tropical forest requires travel through agricultural matrix habitats. We define functional connectivity here as the degree to which landscape structure and composition impedes or facilitates movement of a particular species among habitat patches (Taylor et al. 1993, Tischendorf and Fahrig 2000). Matrix habitats with lower probabilities of successful inter-patch travel, juvenile dispersal, and exchange of genetic material ("harsher" matrices) have been shown 
to decrease the persistence of species in forest fragments (Prugh et al. 2008, Prevedello and Vieira 2009, Kennedy et al. 2010).

Continued forest clearing around many tropical protected areas has increasingly fragmented and isolated protected forests (DeFries et al. 2005, Seiferling et al. 2012), jeopardizing their ability to maintain the species they were established to protect. Costa Rica, with $26 \%$ of its land area in protected areas, is often regarded as a tropical conservation success story (Pagiola 2008, Porras et al. 2013), yet agricultural clearing outside parks has been extensive (Sader and Joyce 1988, Sánchez-Azofeifa et al. 2003). In 1996, the Costa Rican government acknowledged the increasing isolation of their protected area system and enacted several reforms to its national Forestry Law (no. 7575). These reforms banned deforestation and implemented country-wide payments for environmental services (PES) program (Ley Forestal, No. 7575 1996, Porras et al. 2013). In 1997, Costa Rica became an official participant in the Mesoamerican Biological Corridor and drafted a transboundary system of habitat corridors to increase functional connectivity between protected areas for all forest-dependent organisms (DeClerck et al. 2010, Holland 2012). Corridor regions are primarily comprised of private land and are priority targets for PES programs aimed at forest protection, sustainable development, and reforestation (Pagiola 2008, Daniels et al. 2010, DeClerck et al. 2010).

In this study, we investigated whether the establishment of the largest and oldest habitat corridor in Costa Rica, the San Juan-La Selva Biological Corridor (hereafter, the Corridor), was associated with a regional increase in the functional connectivity of lowland rainforests. The Corridor and adjacent protected areas in northeastern Costa Rica have received extensive PES, and the passage of the 1996 Forest Law immediately preceded a $\sim 50 \%$ decrease in clearing of mature rainforests in the region (Fagan et al. 2013). However it is unclear whether a decline in deforestation rates and continued reforestation has led to increased habitat connectivity. Although forest conservation policies implemented in the Corridor region were intended to promote habitat connectivity, the region is an active agricultural zone with continued forest conversion and widespread production of cattle, pineapples, and bananas (Butterfield 1994, Read et al. 2001, Fagan et al. 2013).

Like programs elsewhere in the tropics (Chazdon 2008, Meyfroidt and Lambin 2008), the Costa Rican PES reforestation program has favored tree plantation establishment over natural regeneration. Until recently, payments per hectare for tree plantations were 20 times greater than payments for natural regeneration (Daniels et al. 2010). The reforestation program was established with dual goals: (1) promoting forestry and timber production as an economically sustainable land-use option; and (2) increasing forest cover for biodiversity protection (Daniels et al. 2010), including functional connectivity in the biological corridor system (DeClerck et al. 2010). As a result, tree plantations were exempted from the clearing ban imposed on natural forest (Ley Forestal, No. 7575 1996).

Quantifying the impact of reforestation efforts on forest connectivity in Costa Rica faces two major hurdles. First, determining the extent of reforested areas is challenging because public records and data on the area of tree plantations established is inexact, and tree plantations are difficult to distinguish from secondary forests in satellite imagery (Sterling and Ducharne 2008, Sánchez-Azofeifa et al. 2009). Second, the value of tree plantations for wildlife movement or breeding habitat varies markedly across forest species and with management practices (Carnus et al. 2006, Brockerhoff et al. 2008, Nájera and Simonetti 2010). In northeastern Costa Rica, nonnative timber species with short rotation times make up $\sim 88 \%$ of tree plantations and may be providing only short-term, lowerquality habitat (Barlow et al. 2007, Fagan et al. 2015).

Evaluating the impact of reforestation on connectivity is only meaningful in the context of specific organisms; how frequently organisms move among semi-isolated populations varies markedly across taxa (Taylor et al. 1993, Lees and Peres 2009). Many species within lowland rainforests are dependent on closed forest cover for habitat and have a limited ability to travel outside forest (Gardner et al. 2009, Stork et al. 2009). To evaluate functional connectivity for forest organisms in this region, we examined a representative, well-studied functional group: understory-nesting insectivorous birds. This group is known to be sensitive to forest fragmentation, dependent on forest for breeding habitat, and have limited ability to disperse across open habitat (Sekercioglu et al. 2002, Laurance et al. 2004, Moore et al. 2008, Newbold et al. 2013). These characteristics make this functional group an acceptable indicator for connectivity in the Corridor region (Sigel et al. 2010). The habitat corridor system was established to maintain functional connectivity for multiple forest-dependent taxa (DeClerck et al. 2010), including understory birds.

Through a combination of field playback experiments and literature review, we analyzed the movement ecology and behavior of four selected understory bird species: Myrmeciza exsul (Chestnut-backed Antbird; Thamnophilidae), Henicorhina leucosticta (Whitebreasted Wood Wren; Troglodytidae), Thamnophilus atrinucha (Black-crowned Antshrike; Thamnophilidae), and Glyphorynchus spirurus (Wedge-billed Woodcreeper; Furnariidae). All these species have smaller and more variable local population sizes (one to 20 individuals) in forest patches $<4$ ha in size (Cody 2000, Sekercioglu et al. 2002, Libsch 2005, Roberts 2007). Furthermore, decreasing fragment size is associated with a declining trend in population density with decreasing fragment size for H. leucosticta and M. exsul (Roberts 2007) and higher population turnover and genetic isolation for M. exsul (Losada-Prado 2009, Woltmann et al. 2012a,b), implying that fragments are long-term population sinks. For at least two of our species $(H$. leucosticta and 
TABLE 1. Individual characteristics of each of the selected bird species.

\begin{tabular}{|c|c|c|c|c|}
\hline Characteristic & Myrmeciza exsul & Henicorhina leucosticta & $\begin{array}{l}\text { Thamnophilus } \\
\text { atrinucha }\end{array}$ & $\begin{array}{l}\text { Glyphorynchus } \\
\text { spirurus }\end{array}$ \\
\hline Short name & chestnut & wood & shrike & wedge \\
\hline Foraging height & $\begin{array}{l}\text { low understory, } \\
\text { ground }\end{array}$ & tall understory, ground & $\begin{array}{l}\text { understory to } \\
\text { canopy }\end{array}$ & $\begin{array}{l}\text { understory to canopy, } \\
\text { forest edges }\end{array}$ \\
\hline Territory size (ha) & $1-3$ & 2 & 0.8 & $0.5-1$ \\
\hline $\begin{array}{l}\text { Maximum observed flight } \\
\text { distance }(\mathrm{m})\end{array}$ & $90(90)$ & $50(150)$ & $240(240)$ & $150(250)$ \\
\hline Family & Thamnophilidae & Troglodytidae & Thamnophilidae & Furnariidae \\
\hline Common habitat & $\begin{array}{l}\text { forest, disturbed } \\
\text { forest }\end{array}$ & $\begin{array}{l}\text { intact forest, disturbed } \\
\text { forest, nearby regrowth }\end{array}$ & intact forest & $\begin{array}{l}\text { forest, nearby wooded } \\
\text { pasture }\end{array}$ \\
\hline $\begin{array}{l}\text { Most open habitat } \\
\text { observed in }\end{array}$ & shade coffee, cacao & fern-dominated pasture & forest & wooded pasture \\
\hline
\end{tabular}

Notes: We estimated that $\sim 1 \%$ of individual birds could fly the maximum flight distances shown in parentheses. Maximum flight distance for H. leucosticta and G. spirurus is poorly constrained by existing work (Ibarra-Macias et al. 2011a). Few birds flew directly to forest from pasture at ranges of 100-150 m, instead landing on pasture trees closer to the forest edge. To estimate flight distance for these species, we assumed $25 \%$ of pasture tree birds eventually made it to the forest; this fit an exponential decline in dispersal distance well. Data are drawn from Roper (1996), Woltmann et al. (2013), Robinson et al. (2000), Blake and Loiselle (2012), Moore et al. (2008), Ibarra-Macias et al. (2011a), Tarwater and Brawn (2010), Losada-Prado (2009), and Van Bael et al. (2007).

G. spirurus), difficulties in perceiving and orienting to forest cover at distances $>100-150 \mathrm{~m}$ limit successful long-distance matrix travel (Ibarra-Macias et al. 2011a). These species are rarely observed outside forest, with the exception of G. spirurus, which depends on forest habitat but can forage in wooded pasture near forests (Lindell et al. 2004). The understory-foraging species move within dense shrub or fern cover outside forests and have relatively short flight records from experimental translocations (Table 1). T. atrinucha, with its long flight record but tendency to remain within forest habitats and disappear from small fragments (Roberts 2007, Van Bael et al. 2007, Moore et al. 2008), is more typical among area-sensitive insectivores (Van Houtan et al. 2007).

We combined movement parameters derived from our ecological analysis with existing land cover maps to create alternate graph-theoretic models of landscape connectivity (Urban and Keitt 2001). We used the graph models to assess regional changes in functional connectivity (specifically, the potential for understory bird movement) over the past three decades (1986-2011). We then identified optimal locations for future reforestation within the region described by the Corridor and connected protected areas. We addressed three main questions: (1) Has functional connectivity for understory birds increased since 1996 in the San Juan-La Selva Biological Corridor region? (2) Has expansion of tree plantations served to enhance connectivity for understory birds? (3) Which locations in the landscape are most critical to reforest to improve functional connectivity?

\section{Methods}

\section{Study region}

The northeastern Caribbean lowlands of Costa Rica extend from the central Tilarán Mountains north to the
San Juan River. This warm tropical region has high, constant rainfall $(3.2 \pm 0.8 \mathrm{~m} / \mathrm{yr})$ and relatively little variation in elevation (108 $\pm 98 \mathrm{~m})$ (Fagan et al. 2013). Central ranges of low hills are interrupted by wide river valleys, transitioning to coastal plains and swamps in the east. In the late $1960 \mathrm{~s}$, settlement of this region grew quickly and led to widespread, rapid forest conversion to agriculture at the rate of $2-3 \%$ per year (Butterfield 1994, Sánchez-Azofeifa et al. 1999). In recent decades, land use change has been dynamic. Conversion of mature rainforest continues, but declined after 1996 to $\sim 1 \%$ per year (Fagan et al. 2013). At the same time, extensive natural forest regeneration and tree plantation establishment has occurred, often followed by clearing of both natural regeneration and tree plantations (Read et al. 2001, Morse et al. 2009, Fagan et al. 2013). Pasture for cattle grazing is the most common land use in the region, with large areas of the coastal plains and river valleys in intensive agriculture for pineapples, bananas, sugarcane, heart-of-palm (palmito), and other crops. In addition, selective logging has been an important activity in forest areas located around protected areas in the last $20 \mathrm{yr}$ (Arroyo-Mora et al. 2014).

Despite declines in forest cover, the Caribbean lowlands in Costa Rica currently retain the largest patches of old-growth forest outside protected areas in the country, as well as several large parks protecting lowland rainforest and a flagship charismatic species, the Great Green Macaw (Ara ambiguus; Psittacidae) (Watson et al. 1998, Fagan et al. 2013). In the center of the region, the San Juan-La Selva Biological Corridor $\left(2466 \mathrm{~km}^{2}\right)$ is designed to connect two protected areas, the montane Braulio Carrillo National Park and the Indio Maíz Biological Reserve $\left(3602 \mathrm{~km}^{2}\right)$ across the San Juan River in Nicaragua (Fig. 1). The Corridor includes a mix of private lands and private and public wildlife refuges such as Maquenque Wildlife Refuge, with further connections 


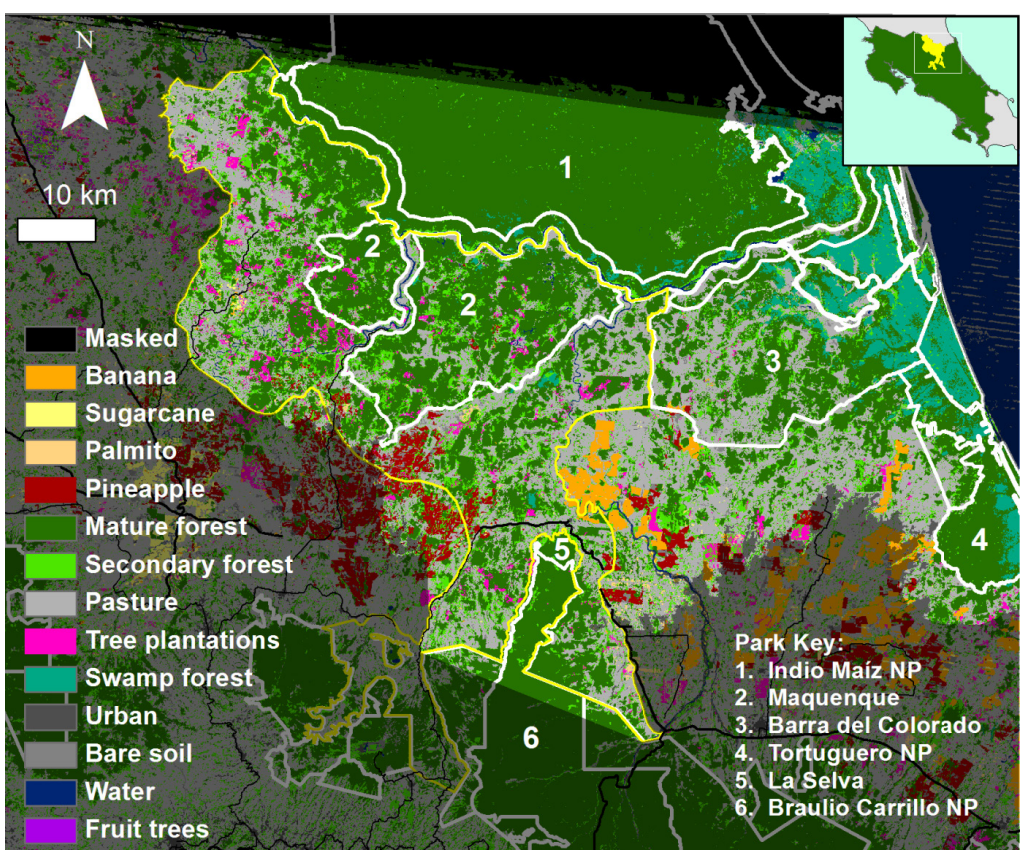

FIG. 1. Land-use map of the study region in 2011; the small inset map of Costa Rica shows the location of the study region and the San Juan-La Selva Biological Corridor (SJLSBC, in yellow). In the main map, the yellow line outlines the SJLSBC, white lines denote protected areas, and the black lines outline main highways. The black masked areas in the main map mark the limits of the satellite image used to create the map; the shaded region was excluded from our connectivity analysis.

via Barra del Colorado Wildlife Refuge to Tortuguero National Park (Fig. 1). From 1986 to 1996, selected farms in the study region received subsidies for planting trees, most of which were nonnative species (Fagan et al. 2013). From 1996 onward, all of the protected areas and private lands within the Corridor region have received numerous multiyear PES contracts for forest protection or the establishment of tree plantations ( 1100 contracts covering $\sim 950 \mathrm{~km}^{2}$; M. E. Fagan, unpublished data). Additionally, throughout Costa Rica, the 1996 Forestry Law bans clearing of natural forests above a certain density and size threshold, which in the Caribbean lowlands typically protects forests $>12 \mathrm{yr}$ in age (Fagan et al. 2013).

\section{Focal species}

The selected understory insectivorous bird species (Myrmeciza exsul, Henicorhina leucosticta, Thamnophilus atrinucha, and Glyphorynchus spirurus) are relatively abundant in fragmented landscapes, well-studied elsewhere in the Neotropics, and responsive to song playbacks. All four species are widely distributed and abundant year-round residents in Neotropical lowland forests, feed primarily on insects, depend on closedcanopy forest for understory nesting habitat, and are highly territorial, actively defending sedentary territories year-round (Stiles et al. 1989, Robinson et al. 2000). The individual characteristics of each species are described in Table 1. Each species varied markedly in maximum observed flight distance and tolerance of open areas (Moore et al. 2008, Ibarra-Macias et al. 2011a).

\section{Bird movement behavior: field experiments}

For our field observations, we measured the movement behavior of adult birds at forest edges. We used territorial song playback experiments to assess bird willingness to cross forest boundaries into matrix habitat ("boundary softness"; Appendix S2: Fig. S1). We measured the distance of intrusion from the forest edge into the adjacent matrix habitat as our response variable. Bird movements were assessed across three habitat types: pastures, native tree plantations, and nonnative tree plantations, all with varying amounts of tree and shrub cover. From 2011 to 2012, during both the breeding (January-May) and nonbreeding (June-August) seasons, studies were conducted at 23 field sites across the Caribbean lowlands (Appendix S2: Fig. S2). Random site location was not possible due to difficulties in obtaining permission to work on private property, but sites were separated more than $1 \mathrm{~km}$ and effort was made to space samples of all three habitat types across the Corridor region (Appendix S2: Fig. S2).

At each site, researchers walked along the edge of a forest patch and used a portable speaker to play male territorial vocalizations from each of the target species. Songs were played at the average measured volume for our four bird species ( $\sim 80 \mathrm{db}$ at $1 \mathrm{~m}$; see Boscolo et al. 2006). When a bird responded to the song playbacks, the researchers retreated $>5 \mathrm{~m}$ from the speaker, crouched, 
and played the species' song until an individual approached the forest edge, for a maximum of $10 \mathrm{~min}$. Once a target species neared the forest boundary, the experiment began (Appendix S2: Fig. S1). A speaker was placed $25 \mathrm{~m}$ into the agricultural habitat, and the song moved to play there. If the bird proceeded out of the forest more than $15 \mathrm{~m}$ into the agricultural matrix, the first speaker was turned off and another activated $50 \mathrm{~m}$ into the agricultural matrix. Individuals had a maximum time limit of $10 \mathrm{~min}$ (Sieving et al. 2000) to travel the $50 \mathrm{~m}$. At the end of each 10-min sample, we recorded maximum habitat penetration distance. We also measured tree basal area and the stem density of saplings and shrubs (with saplings and shrubs defined as $>1.3 \mathrm{~m}$ in height and $<5 \mathrm{~cm}$ in diameter) in a $30 \times 50 \mathrm{~m}$ plot centered on the speaker transect.

For selected individuals, we conducted an additional control playback experiment along the forest edge to compare potential movement in matrix and forest habitats (Appendix S2: Fig. S1). After each experiment, the researchers moved $25 \mathrm{~m}$ before beginning playback of other species, and playbacks of the same species were separated by a minimum of $250 \mathrm{~m}$ to avoid sampling the same individual. The paired control-edge trials and edge-only trials were analyzed separately using general linear models in $\mathrm{R}$ 2.14 ( $\mathrm{R}$ Core Team 2012). In each analysis, we predicted maximum habitat penetration distance as a function of bird species and the habitat variables described previously.

\section{Linking bird movement behavior to functional connectivity}

Information on the focal species from our field experiments and from other studies was used to determine parameter values for a population connectivity model (Fig. 2A). Our literature review focused on movement and reproductive ecology, and is referenced later with regards to the selected connectivity models and parameter values. We sought to determine species' movement responses to habitat availability and configuration, their dispersal through matrix (non-forest) habitats, and their potential to successfully breed in fragmented forest habitat. When information was insufficient for a selected species, we estimated species characteristics from our field observations and from studies on other similar understory insectivorous birds.

\section{Connectivity analysis: landscape maps}

We modified existing 30-m resolution land-use maps of northeastern Costa Rica to analyze habitat connectivity (Figs. 1 and 2A; see Fagan et al. 2013 and Appendix S1 for details of map generation and accuracy assessment). The resulting land cover maps delineated 13 land cover types (Appendix S1: Table S1) over five time periods, from 1986 to 2011 , with $>90 \%$ accuracy (Appendix S1: Table S2).

We focused our analysis of forest connectivity on the Corridor and adjacent lowland areas with high forest cover that were located between Maquenque National
Wildlife Refuge and Braulio Carrillo and Tortuguero National Parks (Fig. 1). A least-cost path linkage analysis using Linkage Mapper software (McRae and Kavanagh 2011) was used to delimit all land in 1986 that lay within a wide range of "resistance" values from the least-cost paths between the three parks (generic forest:non-forest resistance of 1:100 (McRae and Kavanagh 2011), maximum cumulative resistance value of 20000). This $5825-\mathrm{km}^{2}$ subset of the region (Fig. 1) effectively selected all lowland ( $<500 \mathrm{~m}$ in elevation) areas with high forest cover, while including adjacent land-cover types and the Indio Maíz Biological Reserve.

\section{Graph connectivity model}

We modeled the functional connectivity, or potential for movement among habitat patches, of our four species using a graph-theoretic, node-based model implemented in the program Graphab 1.2 (Foltête et al. 2012). In this graph model, patches of core forest habitat, or nodes, are located on a raster map and surrounded by habitat with varying resistance values for animal movement. Nodes are connected by links that take the least-cost path along the resistance raster surface. For our selected connectivity metrics, the frequency of travel from node to node is modeled as an exponential decay in the probability of arrival at a maximum distance (Fig. 2B), and thus can be modified for different species based on biological data about maximum flight distances or occupancy patterns (Saura and Pascual-Hortal 2007).

For our resistance map, we set a minimum core patch size of 4 ha that is the minimum fragment size for stable populations of the target species (Cody 2000, Sekercioglu et al. 2002, Libsch 2005, Roberts 2007, Losada-Prado 2009). Edges were defined as the outer $30 \mathrm{~m}$ of forest patches, and had little effect on movement in our model because edge forest pixels had the same low resistance to movement as core forests. We chose to model all habitat areas as either forest (resistance weight 1 for edge and core forests) or non-forest (resistance weight 90); tree plantations were set as forest or non-forest in a given model run (see following section). Our resistance weights were set based on field observations of behavior at forest edges (see Results), and a literature review of the maximum distance understory insectivores will travel within forest to avoid open habitat (Bélisle and Desrochers 2002, Laurance and Gomez 2005, Boscolo et al. 2008, Woltmann et al. 2012b). Preliminary analyses showed that higher non-forest resistance weights did not alter link locations or lengths; a resistance weight of 90 was both biologically realistic (see Discussion) and convenient for conversion between resistance and map distances measured in $30-\mathrm{m}$ increments.

\section{Graph connectivity scenarios}

Because of uncertainty about species-specific traits and their responses to landscape structure and composition, we 

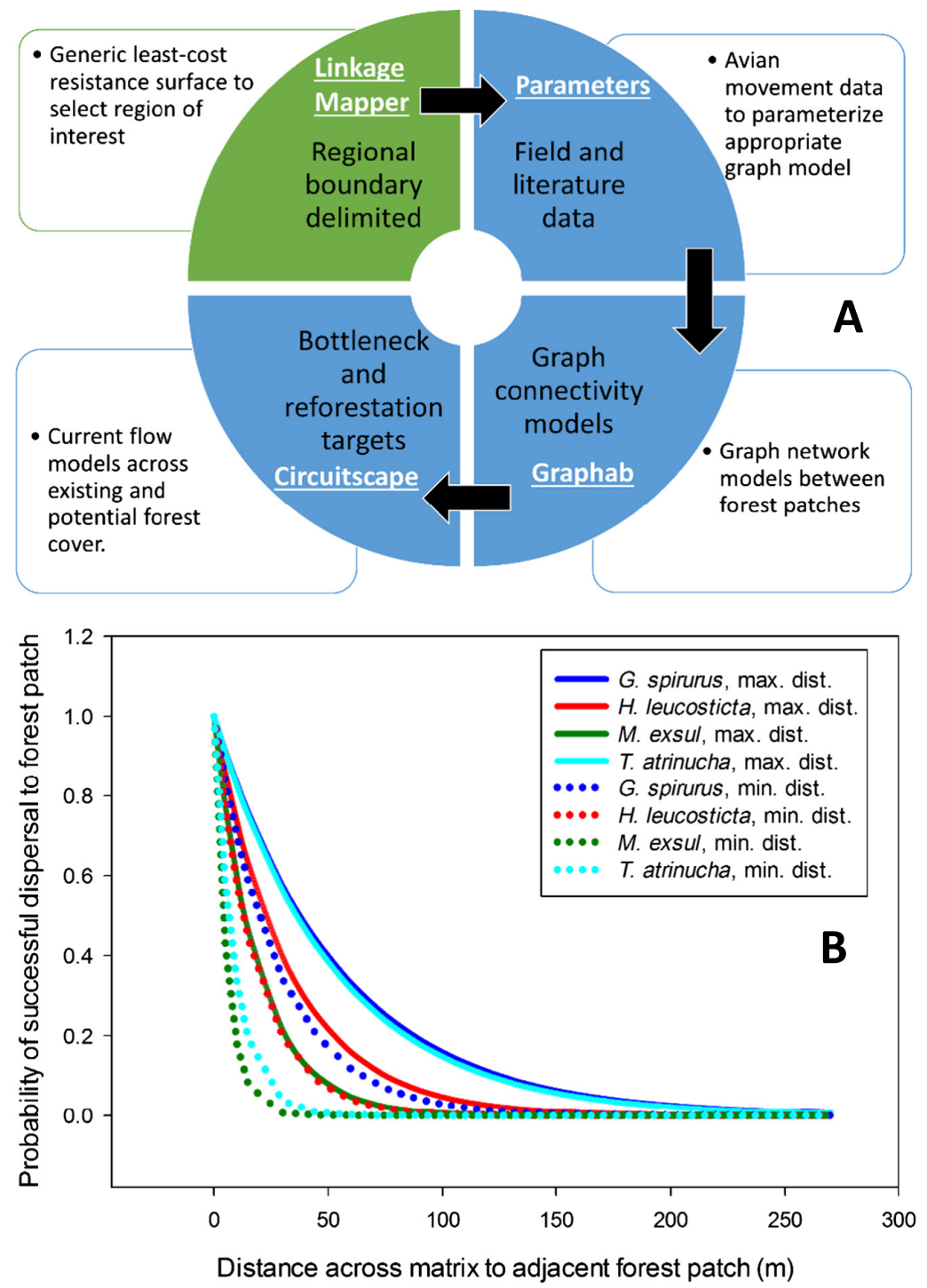

FIG. 2. (A) A conceptual diagram describing the connectivity modeling process (black text) and tools (white text). The top left model process green is general across species. The other three model processes were parameterized separately for each bird species. See text for further details and references. (B) A set of parameters derived from field data: the probability of successful arrival at neighboring core forests in the graph model, used for Probability of Connectivity (PC) and Equivalent Connected Area (ECA) metric calculations. Probability declined as a negative exponential function, with a 0.01 probability of reaching a set distance, and a maximum possible distance of $250 \mathrm{~m}$. Species were Myrmeciza exsul (Chestnut-backed Antbird), Henicorhina leucosticta (Whitebreasted Wood Wren), Thamnophilus atrinucha (Black-crowned Antshrike), and Glyphorynchus spirurus (Wedge-billed Woodcreeper).

modeled functional connectivity in a sensitivity analysis using a variety of different, biologically plausible parameter values derived from the literature and our field work. We varied graph parameters across eight possible travel distances and six map scenarios for each of the five image dates, generating 30 different resistance maps with a total of 240 different graph networks (Table 2). For each of the four species, we assigned two maximum matrix travel distances: a lower bound, with the maximum observed travel distance from our experiment (Fig. 3), and an upper bound, using literature-derived record distances from flight trial experiments (Tables 1 and 2). We then assumed that in normal travel, an individual would have a $1 \%$ chance of traveling to its matrix travel distance limit (Fig. 2B). The assumption of $1 \%$ travel success conservatively estimates a high probability of travel to maximum distance. This estimate is based on high rates of failure $(>80 \%)$ in experimental translocations of forest birds that were well short of their maximum possible flight distance (Table 1; Moore et al. 2008, Ibarra-Macias et al. 2011a, Awade et al. 2011).

Next, for each species, we created six different resistance map scenarios (Table 2). First, we varied the importance of tree plantations for bird movement in three scenario pairs. In the "forest" scenarios, all tree plantations had 
TABLE 2. Summary outline of the graph model sensitivity analyses for each image date, showing the six travel scenarios and eight different flight distances for the bird species.

\begin{tabular}{|c|c|c|}
\hline Main travel scenario, by width & Description & Maximum flight distances \\
\hline Narrow width & All forest elements are usable for movement. & \\
\hline Forest & $\begin{array}{l}\text { All core and edge forests and tree plantations have resistance } \\
\text { value of } 1 \text {; non-forest resistance is } 90 .\end{array}$ & Wedge $(129,250 \mathrm{~m})$ \\
\hline Open & $\begin{array}{l}\text { Non-forest and tree plantation resistance is } 90 \text {; all core and } \\
\text { edge forests have resistance of } 1 .\end{array}$ & Wood $(85,150 \mathrm{~m})$ \\
\hline Non-harvest & $\begin{array}{l}\text { Like forest model, but tree plantations never are converted to } \\
\text { other land-uses after establishment. }\end{array}$ & Shrike $(42,240 \mathrm{~m})$ \\
\hline Broad width & $\begin{array}{l}\text { Edge-dominated forest elements }<60 \mathrm{~m} \text { in width or }<1 \text { ha in } \\
\text { size are equivalent to non-forest for movement. }\end{array}$ & \\
\hline Forest & Same as for narrow width & Chestnut $(27,90 \mathrm{~m})$ \\
\hline Open & Same as for narrow width & \\
\hline Non-harvest & Same as for narrow width & \\
\hline
\end{tabular}

Note: Maximum flight distances are shown (lower, upper), and have 1\% chance of arrival at maximum distance. The six travel scenarios and eight flight distances were combined in the sensitivity analysis, with 48 graph models for each of the five image dates (240 models in total).

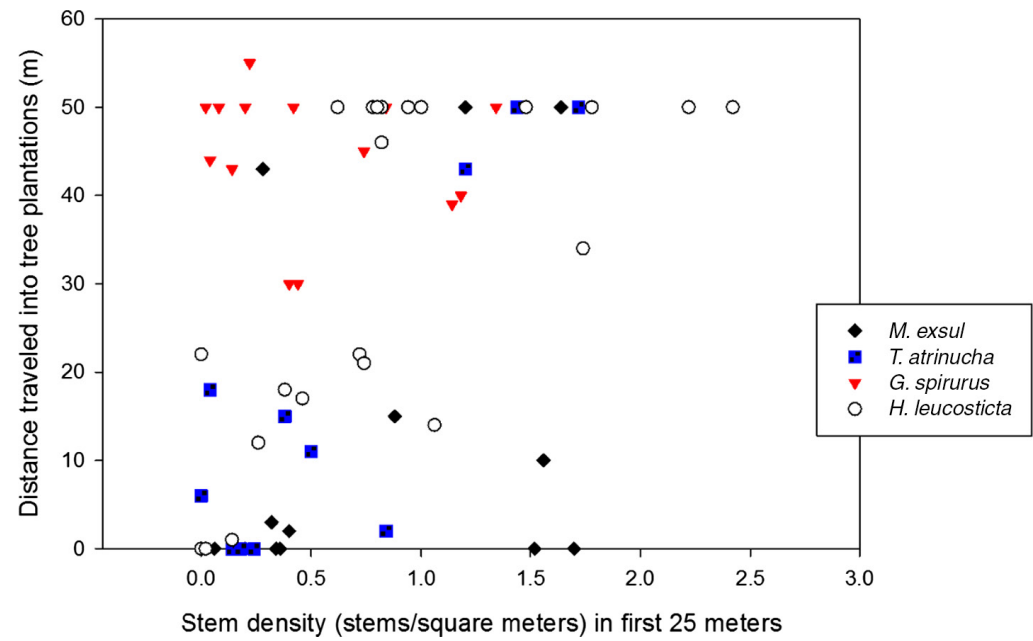

FIG. 3. In the playback experiment, travel distance into tree plantations (toward the playback speakers) was positively related to understory stem density for three of the four species, all except G. spirurus. For the details of the GLM model that describes this relationship, see Table 3, GLM 3. The overall $R^{2}$ of the GLM model was 0.60 .

the same resistance to travel as forest, which might occur if all tree plantations had dense, tall understory vegetation. In the "open" scenarios, tree plantations had the same resistance to travel as pasture and other matrix habitat, which might occur if all tree plantations were harvested or if all tree plantations had low shrub density. Finally, in the "non-harvest" scenarios, we assigned tree plantations the same resistance as forest and did not allow tree plantations to be harvested between land cover map dates. These non-harvest scenarios tested the role plantation harvests may play in decreasing connectivity and movement between forest fragments for understory birds. The non-harvest scenarios also removed the influence of the shorter harvesting rotation time for nonnative tree plantation species (Fagan et al. 2015). For each of the scenarios, we did not distinguish between native and nonnative tree plantations because our playback experiment results indicated that the understory birds studied did not discriminate between the two plantation types.

In addition, for each scenario type, we created two secondary scenarios relating to movement through narrow, disturbed forests (Table 2). In the "narrow" width scenario, birds could freely travel through narrow forest corridors and small forest patches. In the "broad" width scenario, birds could not travel easily in forest corridors $<60 \mathrm{~m}$ in width or in small forest patches $<1$ ha in size. The specific values of the movement constraints in these scenarios were selected based on field observations and the literature. The limited number of available studies suggested that understory insectivores either pass freely through 10-25 m wide forest corridors (narrow width) or experience population decline at corridor widths $<200 \mathrm{~m}$ (broad width) (Sieving et al. 2000, Castellón and Sieving 2006, Lees and Peres 2008). 


\section{Graph analysis: connectivity metrics}

For each graph network scenario, we calculated connectivity metrics to summarize differences in connectivity at the landscape, patch, and link scale. Landscape scale measures integrated regional connectivity, patch scale refers to the importance of core forest patches for connectivity, and link scale refers to the importance of leastcost connections between forest patches.

We used the probability of connectivity (PC) metric to characterize functional connectivity at these three scales (Saura and Pascual-Hortal 2007). At the landscape scale, the PC metric describes the "probability that two animals randomly placed within the landscape fall into habitat areas that are reachable from each other (interconnected) given a set of $n$ habitat patches and the connections $\left(p_{i j}\right)$ among them" (Saura and Pascual-Hortal 2007). Because of its superior properties, the PC metric has been used to measure functional connectivity in a number of temperate and tropical studies (e.g., Awade et al. 2011, Mazaris et al. 2013). The PC metric, which varies between 0 and 1, permits biologically realistic dispersal parameterization and takes into account changes in habitat area and inter-patch connectivity (Awade et al. 2011). It is calculated as follows:

$$
\mathrm{PC}=\frac{\sum_{i=1}^{n} \sum_{j=1}^{n} a_{i} a_{j} p_{i j}^{*}}{A_{\mathrm{L}}^{2}}
$$

where $a_{i}$ and $a_{j}$ are the areas of habitat patches $i$ and $j$, respectively, $p_{i j}^{*}$ is the highest probability of movement among all possible paths between patches $i$ and $j$, and $A_{\mathrm{L}}$ is the total area of habitat and non-habitat patches in the landscape (i.e., total landscape area). Graphab estimates $p_{i j}^{*}$, the probability of successful dispersal, as a negative exponential decline with distance (Fig. 2B). This estimate provided a reasonable fit for the dispersal of a Brazilian understory bird, with some potential to overestimate dispersal (Awade et al. 2011).

By taking the square root of the numerator of the PC equation, an additional metric with units of area can be derived. This equivalent connected area (ECA) metric can be directly related to changes in habitat area that occur concurrently with changes in habitat connectivity (Saura et al. 2011). If changes over time in habitat area are small while positive or negative changes in ECA are large, that implies that habitat was gained or lost in areas strategically important for maintaining animal movement among habitat patches (Saura et al. 2011).

At patch and link scales, the importance of a given patch or link for functional connectivity can be assessed by removing it and measuring the global proportionate loss of PC, or delta PC (dPC), which is the difference in $\mathrm{PC}$ divided by the original PC value (Saura and Rubio 2010). Further, dPC can be decomposed into three components: dPC-Intra (intrapatch connectivity: directly related to habitat area), dPC-Flux (the contribution of a patch via direct dispersal to/from its neighbors), and dPC-Connector (how much the loss of a patch or link decreases dispersal between neighboring patches) (Saura and Rubio 2010).

\section{Graph analysis: statistical analysis}

Because small uncertainties in land cover map accuracy propagated through our connectivity model (Appendix S1: Table S2), we used statistical analysis of forest cover and PC metrics over time to highlight consistent results across model scenarios. At the landscape scale, we used a general linear model to compare PC values among the 240 parameter scenarios, with model scenario types, travel distance, and map date as predictors of landscapescale PC values. We also further compared shifts in the value of the ECA metric with changes in total forest area.

At the patch scale, changes in forest patch location, patch shape, and the value of landscape PC across years and models made it difficult to statistically compare patch dPC between individual forest fragments. But for illustration of this variation, we mapped patch $\mathrm{dPC}$ values over time for four out of 48 possible models.

At both the patch and link scale in the forest scenario, we assessed whether tree plantations had higher or lower importance for functional connectivity than forest patches. We compared a metric relatively uncorrelated with area, dPC-Connector, across model types. Because $99 \%$ of patches and links had extremely low importance $(<0.001 \%)$ for inter-patch connectivity, we restricted our analysis to the top $2 \%$ of dPC-Connector values. We then compared the relative number of tree plantation and forest patches in the top $2 \%$ in a chi-square analysis, and tested whether mean dPC-Connector values differed for forest and tree plantation patches using a general linear model implemented in the $\mathrm{R}$ statistics package v. 2.14.

\section{Prioritizing new reforestation and natural regeneration}

We conducted a spatial prioritization analysis to identify locations critical for maintaining and improving landscape connectivity (see Appendix S4 for details of the prioritization analysis methodology). The prioritization methodology combined the global connectivity metrics from our graph connectivity analysis with further information from circuit flow analysis (Circuitscape; McRae and Beier 2007, McRae et al. 2008). We identified existing habitat bottlenecks to connectivity (i.e., constrictions in the optimal flow paths of animal movements, where paths converge;McRae et al. 2012). We also identified where future reforestation could alter connectivity the most, and then simulated the potential impact on connectivity of actually reforesting the selected high-priority pasture land.

\section{Results}

\section{Field experiments and observations}

Field playback studies of species movement behavior revealed that three of the four species traveled $30-50 \mathrm{~m}$ 
farther along secondary and mature forest edges than into agricultural matrix habitats $(P<0.0001$, Table 3$)$, while G. spirurus traveled equally well in forest and matrix habitats $(P=0.13$, Table 3, Appendix S2: Fig. S3). In the matrix-only experimental trials, travel distance did not differ among native and nonnative tree plantation species $(P=0.95$, Table 3$)$ and they were combined in further analysis. In the experimental model with the lowest AIC,

TABLE 3. Best GLM models (by lowest AIC) for playback experiments.

\begin{tabular}{|c|c|c|c|c|c|c|c|}
\hline Variable & Deviance & $\mathrm{df}$ & $F$ & $P$ & Mean & SE & $\operatorname{Pr}(>|t|)$ \\
\hline \multicolumn{8}{|l|}{ GLM 1} \\
\hline Species & 29948 & 4 & 25.94 & $<0.0001$ & & & \\
\hline Chestnut & & & & & 51.54 & 7.57 & $<0.0001^{* * *}$ \\
\hline Shrike & & & & & 43.74 & 6.27 & $<0.0001^{* * *}$ \\
\hline Wedge & & & & & 10.88 & 7.11 & 0.14 \\
\hline Wood & & & & & 31.01 & 6.59 & $<0.0001^{* * *}$ \\
\hline Habitat & 1407 & 1 & 4.88 & 0.04 & & & \\
\hline Tree plantations (TP) & & & & & -13.41 & 6.07 & $0.04^{*}$ \\
\hline \multicolumn{8}{|l|}{ GLM 2} \\
\hline Species & 7870.2 & 2 & 15.96 & $<0.0001$ & & & \\
\hline Intercept & & & & & 2.82 & 5.58 & 0.62 \\
\hline Wedge & & & & & 27.04 & 8.30 & $0.0017^{* *}$ \\
\hline Wood & & & & & 11.05 & 7.11 & 0.12 \\
\hline Habitat & 7666.8 & 2 & 15.55 & $<0.0001$ & & & \\
\hline Native tree plantation & & & & & 0.55 & 8.33 & 0.95 \\
\hline Pasture & & & & & -3.43 & 7.42 & 0.65 \\
\hline Stem density & 3010.1 & 1 & 12.21 & 0.001 & & & \\
\hline Mean stem density & & & & & 10.08 & 2.75 & $0.0004^{* * *}$ \\
\hline Native tree $\mathrm{Ba}$ & 436.2 & 1 & 1.77 & 0.19 & & & \\
\hline Native tree basal area & & & & & 0.02 & 0.02 & 0.17 \\
\hline Species:habitat & 1227.9 & 4 & 1.25 & 0.30 & & & \\
\hline Wedge:native TP & & & & & 9.71 & 11.79 & 0.41 \\
\hline Wood:native TP & & & & & 12.25 & 10.61 & 0.25 \\
\hline Wedge:pasture & & & & & -12.88 & 10.69 & 0.23 \\
\hline Wood: pasture & & & & & -3.51 & 9.56 & 0.71 \\
\hline \multicolumn{8}{|l|}{ GLM 3} \\
\hline Species & 52902 & 4 & 69.21 & $<0.0001$ & & & \\
\hline (Intercept) & & & & & -0.60 & 4.63 & 0.90 \\
\hline Shrike & & & & & -3.89 & 5.14 & 0.45 \\
\hline Wedge & & & & & 18.66 & 4.44 & $<0.0001^{* * *}$ \\
\hline Wood & & & & & 5.16 & 3.88 & 0.19 \\
\hline Habitat & 7400 & 1 & 38.73 & $<0.0001$ & & & \\
\hline $\mathrm{TP}$ & & & & & 2.42 & 6.47 & 0.71 \\
\hline Stem density & 4391 & 1 & 22.98 & $<0.0001$ & & & \\
\hline Mean stem density (Stem) & & & & & 12.09 & 5.65 & $0.03^{*}$ \\
\hline \multicolumn{8}{|l|}{ Native tree $\mathrm{Ba}$} \\
\hline Native tree basal area (BA) & 885 & 1 & 4.63 & 0.03 & 0.02 & 0.01 & 0.16 \\
\hline Species:habitat & 1164 & 3 & 2.03 & 0.11 & & & \\
\hline Shrike:TP & & & & & 6.52 & 8.94 & 0.47 \\
\hline Wedge:TP & & & & & 21.75 & 8.41 & $0.01^{*}$ \\
\hline Wood:TP & & & & & 2.68 & 8.38 & 0.75 \\
\hline Species:stem & 4725 & 3 & 8.24 & $<0.0001$ & & & \\
\hline Shrike:stem & & & & & 5.02 & 7.79 & 0.52 \\
\hline Wedge:stem & & & & & -14.86 & 6.66 & $\mathbf{0 . 0 3}^{*}$ \\
\hline Wood:stem & & & & & 10.62 & 6.96 & 0.13 \\
\hline
\end{tabular}

Notes: In GLM 1, travel distance in control:experimental pairs is the dependent variable, and intercept is set to zero for species; parameter estimates are for forest travel minus pasture travel. In GLM 2, travel distance in native vs. exotic TP (three of four species) is the dependent variable, and intercept refers to travel distance of Chestnut in exotic TP. In GLM 3, travel distance in pastures and TP (all species) is the dependent variable and intercept refers to travel distance of Chestnut in pastures. Multiple comparisons were significant $(P<0.05)$ when $t$ tests were significant, and all models are highly significant. Important nonsignificant effects are highlighted in bold italics; parameter estimates are in units of meters. 
the travel distance of three of the four species was positively related only to understory stem density $(P<0.03$, Fig. 3) and otherwise did not differ between tree plantations and pastures $(P<0.71$, Table 3$)$. G. spirurus flew farther than the other species $(P<0.0001)$, farther in tree plantations than pastures $(P<0.01)$, and its travel distance was not increased by understory stem density $(P<0.03$, Table 3, GLM 3). Understory stem density varied fourfold across sites, but was often close to zero in pastures and higher in tree plantations $(P<0.0001$; Appendix S2: Fig. S4). Maximum observed travel distances in pastures are shown in Table 2 (maximum flight distances: the lower bound for the graph model).

\section{Linking observations to a connectivity model}

The strong preference of the species in our study for travel in forested or wooded habitats and the low mean experimental travel distances in open pasture led us to model our landscape as forest or non-forest for estimating connectivity. We rarely observed short flights across open forest gaps $(12-20 \mathrm{~m})$ for the target species, but none of the species hesitated to approach forest edges for brief periods (M. E. Fagan, personal observation). Remaining uncertainty about the utility of tree plantations and narrow forest corridors for travel led to the construction of the different model scenarios (Table 2).

\section{Graph scenarios: changes in landscape connectivity over time}

Landscape functional connectivity, as measured by the PC metric, declined from 1986 to 2011 across all scenarios and across all flight distances $(P<0.0001$, Appendix S3: Table S1, Fig. 4). The rate of decline in connectivity did not differ among flight distances and forest scenarios $(P>0.5$, interactions not significant; Fig. 4$)$ and functional connectivity declined linearly when the model decreased travel distance $(P<0.0001$; Appendix S3: Table $\mathrm{S} 1$ and Fig. S1). However, the broad-width sub-scenario showed a higher rate of decline in functional connectivity over time than the narrow-width sub-scenario $(P<0.0002$, year by width interaction; Fig. 4).

For the narrow-width sub-scenarios, this $14.5 \%$ average loss in connectivity across models exceeded a $6.6 \%$ relative decline in core forest area over $25 \mathrm{yr}$ (Fig. 4B, Appendix S3: Table S2), indicating a loss in inter-patch connectivity in addition to habitat area (Saura et al. 2011). For the broad-width sub-scenarios, a $21.2 \%$ mean loss in connectivity was observed across models relative to a $6.8 \%$ relative decline in core forest area. In all scenarios, the rate of loss of regional connectivity was highest between 1996 and 2005. From 2005 to 2011, an increase in connectivity occurred that was more marked $(105 \%$ greater on average) for the narrow-width models. The recent small increase in connectivity in both the narrow and broad-width models occurred despite continuing declines in core forest area (Fig. 4, Appendix S3: Table
S2). As core forest decreased from 2005 to 2011, the area of secondary forest increased, implying that extensive, edge-exposed regrowth occurred outside core forests (i.e., small fragments and riparian areas).

At the patch scale, we observed distinct spatiotemporal patterns in declines in forest patch importance for functional connectivity (dPC). Across all time periods, large declines in patch $\mathrm{dPC}$ were observed within and to the south of Barra del Colorado Wildlife Refuge (Fig. 5). From 1986 to 1996, patch dPC decreased in the vicinity of Braulio Carrillo and increased in the central and northern Corridor (Fig. D1). This pattern was reversed from 1996 to 2011, for a net effect (1986-2011) of spatially intermixed gains and declines (Fig. 5); net declines tended to occur in "bridge" patches that connected to larger patches, like the Indio Maíz Biological Reserve (Fig. 5). Patterns were similar across flight distances, but the broad-width model had more widespread net declines in patch dPC (Fig. D1).

\section{Graph scenarios: effect of tree plantations}

At the landscape scale, removing tree plantations from the landscape (open scenario), or making them persist longer (non-harvest scenario), had no significant effect on PC $(P=0.83$, Fig. 4). For models with maximum travel distances greater than $128 \mathrm{~m}$, there is indication of a recent nonsignificant decline in PC in the open scenario (e.g., Fig. 4). However, this difference in connectivity (for the 2011 narrow models, a $\sim 0.87 \%$ decline in PC) is much smaller than the $1.9 \%$ difference in forest area that results from removing tree plantations in 2011 (Appendix S3: Fig. $\mathrm{S} 1)$. At the patch and link scales, tree plantation patches and links to tree plantations were less likely than forest patches and links to be critical for inter-patch connectivity (Figs. 6 and Appendix S4: Fig. S2). Tree plantations patches and links were less abundant than expected in the top $2 \%$ of dPC-Connector values ( $P<0.0001$; Fig. 6$)$. Even after accounting for differences in area with forest patches (model not shown), tree plantations had lower mean values in the top $2 \%$ of patches $(P<0.02$ and $P<0.0001$, respectively, for patches and links; Appendix S4: Fig. S2).

\section{Bottlenecks for reforestation}

Current bottlenecks and key bridges for connectivity are shown in Fig. 7 along with key areas for future reforestation. Bottlenecks and bridges to existing habitat are largely confined to junctions between large and mediumsized patches in the western Corridor. Priority areas for future reforestation extend down all the river valleys of the Corridor and also eastward on multiple different paths between La Selva Biological Station and Tortuguero National Park. High-priority areas for reforestation are adjacent to the majority of identified bottlenecks, and make up $0.1 \%$ of the total land area (582 ha). Actually reforesting all of the priority areas (1\% of the total land area) would, assuming no additional loss in forest area 

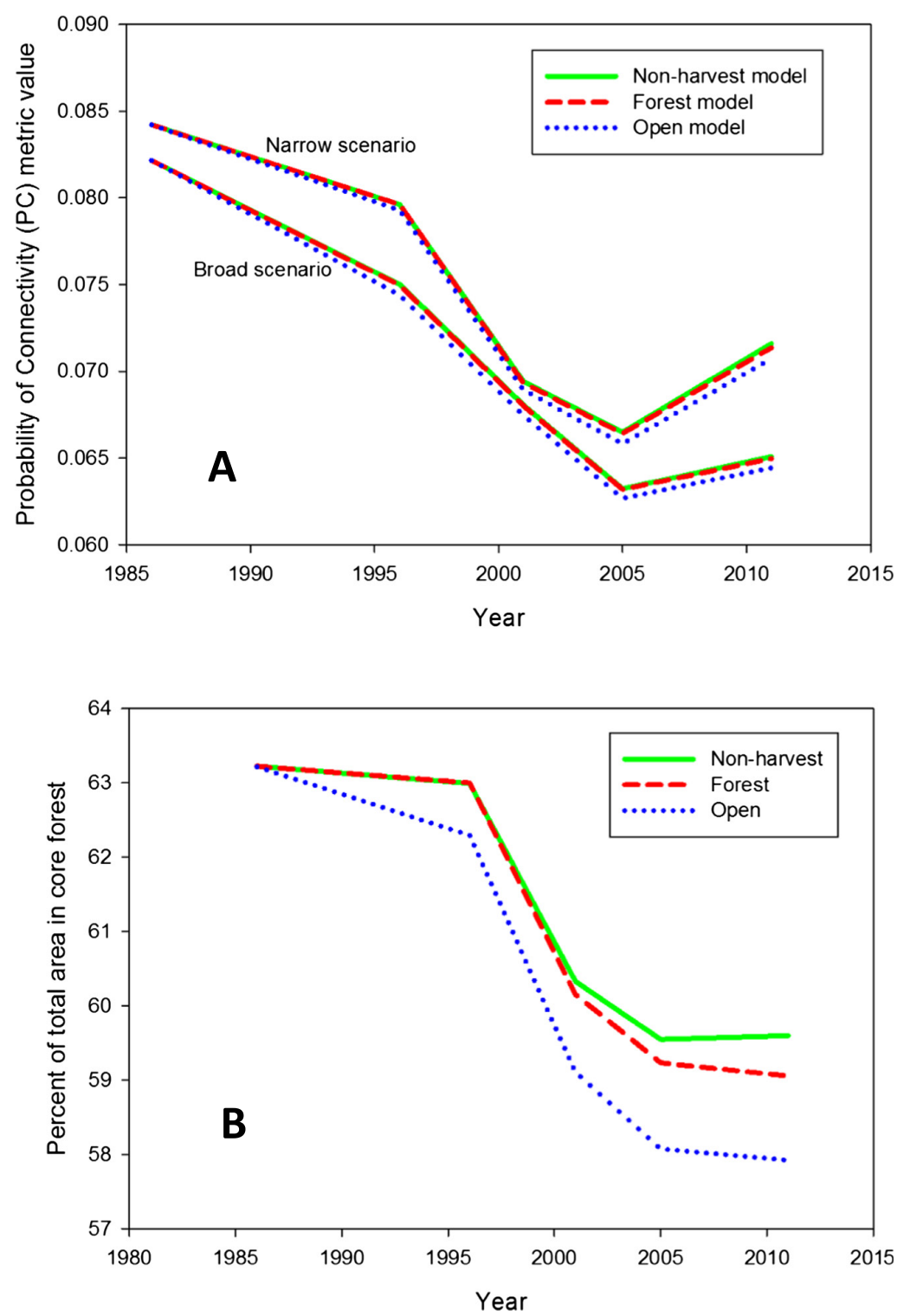

FIG. 4. (A) Declines in landscape functional connectivity over time, as measured by the Probability of Connectivity (PC) metric. The six sensitivity scenarios are shown for the models with a maximum flight distance of $250 \mathrm{~m}$. In the narrow scenario, there was a $14.5 \%$ decline in connectivity from 1986 to 2011 with only a $6.6 \%$ decline in core forest area. In the broad scenario, there was a $21.2 \%$ decline in connectivity with a $6.8 \%$ decline in core forest area. In 2011, removing tree plantations in the open model caused declines in connectivity of $0.87 \%$ (narrow scenario) and $0.82 \%$ (broad scenario) relative to the all forest model. (B) Declines in core forest area ( $>4$ ha in size) as a percentage of the landscape from 1986-2011, shown for the three narrow scenarios. The broad scenario values were quite similar (Appendix S3: Table S2).

from the forest scenario in 2011, increase the ECA by $1.99 \%$ on average across models (Appendix S5: Table S1). Targeted tree plantations would have roughly four times the connectivity impact of existing tree plantations, which occupy $2 \%$ of the total land area and increase connectivity by only $0.87 \%$.

\section{DisCUSSION}

Critical evaluation of conservation programs is essential for effective usage of conservation funds
(Naidoo et al. 2006). Policy programs to enhance habitat connections between protected areas are increasingly considered integral to park function in a changing world (Heller and Zavaleta 2009, Hilty et al. 2012). In forested landscapes, reforestation programs are commonly employed to restore landscape connectivity (Hilty et al. 2006, Locatelli et al. 2015), and reforestation is a rapidly expanding global land use (Sandel and Svenning 2013, FAO 2015), often in the form of commercial tree plantations (Sterling and Ducharne 2008). However this study is one of relatively few to examine how planned or 


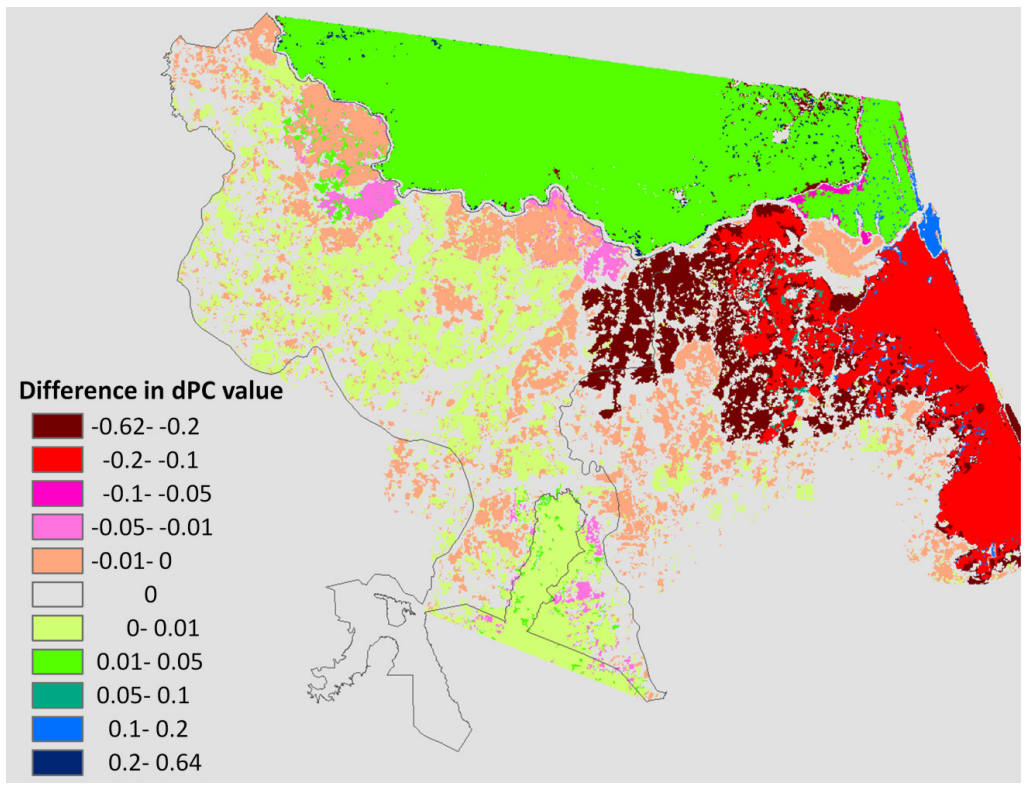

FIG. 5. Net changes in patch-level importance for functional connectivity (as measured by delta landscape Probability of Connectivity, or dPC (see text)) from 1986 to 2011. We show patch connectivity values for the narrow forest scenario with a $250 \mathrm{~m}$ maximum movement distance (Table 2). The largest declines were in the east (Barra del Colorado Wildlife Refuge and Tortuguero National Park), with smaller losses in the central and northern SJLS Biological Corridor (inset gray line). Other sensitivity scenarios had largely similar patterns (Appendix S3: Fig. S1).

implemented reforestation programs alter functional connectivity between forest patches. Ferraz et al. (2012) reviewed the potential impact of a proposed Atlantic forest restoration project on understory bird populations and Nogués and Cabarga-Varona (2014) examined the effect of tree plantations on forest connectivity in northern Spain. Other studies have demonstrated increased animal movement through tree plantations and young secondary forests (Tubelis et al. 2007, Van Houtan et al. 2007, Zurita and Bellocq 2010), but understanding the degree to which reforestation increases local movement between forest patches is just the first step in evaluating its effect on functional connectivity. Equally important is tracking the persistence of reforested areas across large landscapes, understanding how reforestation management alters habitat quality for different dispersing taxa, and assessing how to target reforestation in the landscape to maximize regional connectivity. All of these factors influence how reforestation programs alter the availability and location of suitable dispersal habitat for a given species.

Although considerable debate exists regarding whether PES payments have led to additional forest protection in Costa Rica (Morse et al. 2009, Daniels et al. 2010, Robalino and Pfaff 2013), their role in expanding tree plantations in northeastern Costa Rica is less controversial (Morse et al. 2009, Fagan et al. 2013). Our results indicate that PES for forest protection and reforestation did not cause a net increase in connectivity over time for understory birds in the focal Corridor region. Functional connectivity for understory insectivorous birds declined faster than habitat loss over time for all connectivity scenarios and species travel distances, by 13-22\% (Fig. 4). With low net forest cover change in the region from 1986 to $2011(-4.9 \%$ in total, or $-0.2 \%$ per year), this rapid decline in connectivity was unexpected, although it is partly explained by the $6.6 \%$ decline in area of core forest patches ( $>4$ ha in size) in that time period, particularly in the Barra del Colorado Wildlife Refuge. The observed decline in connectivity in the corridor region parallels connectivity losses in other, highly fragmented landscapes (Saura et al. 2011).

The relatively slow rate of change in forest habitat and connectivity after 1996 could be ascribed to forest conservation policies taking effect (Fagan et al. 2013). However a net recovery in connectivity was not observed despite extensive tree planting, most likely because of suboptimal location selection for improving connectivity (Fig. 6, Appendix S3: Table S2). It is likely that PES prevented greater losses in connectivity between 1996 and 2011 by protecting remnant patches of mature forest (Fagan et al. 2013).

Given the importance of riparian forests and wooded pastures for connectivity in our models, we argue that more information is needed on how forest organisms use small or diffusely forested corridors for dispersal. Riparian forests and wooded pastures are especially common landscape features in Latin America (DeClerck et al. 2010) and other forested landscapes. Like many other taxa, the species in this study had a "corridor function" (i.e., the narrowest forest element they will use for extended travel) that was poorly constrained by the 

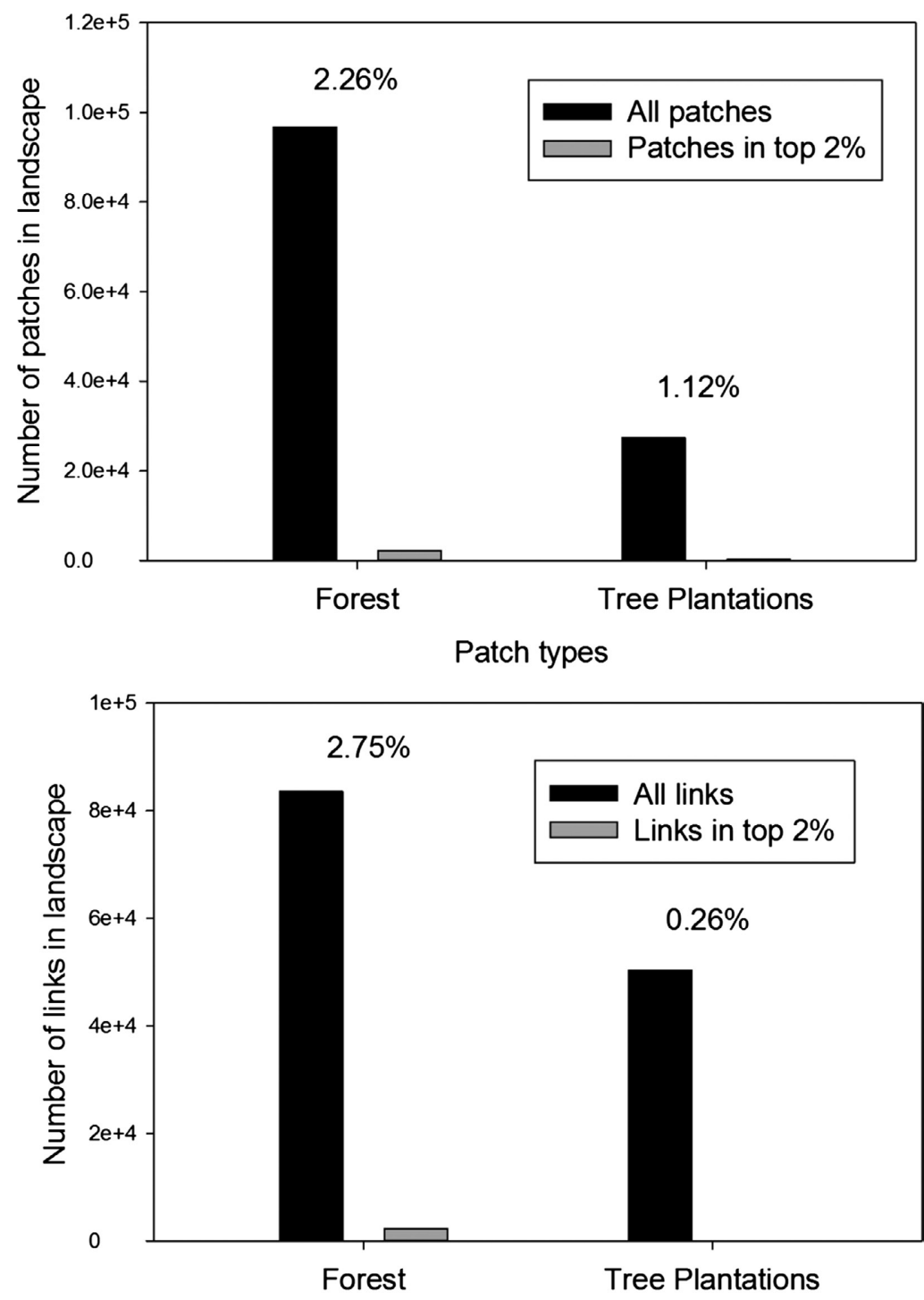

Link types

FIG. 6. Proportion of patches and links that are in the top $2 \%$ of connectivity values for the dPC-Connector metric, across models. The percentage of total patches and links that are high value for connectivity is labeled for each land use type. Tree plantation links and patches that are important for connectivity are proportionately less common than forest links and patches that are important for connectivity $(P<0.0001$, chi-square analysis).

literature (Knowlton and Graham 2010). The recent rise in connectivity from 2005 to 2011 was $\sim 105 \%$ greater in models when species were permitted to use narrow forest corridors. This suggests that recent forest regrowth occurred primarily in small forest fragments and riparian forests, and that travel through riparian forests might a key component of maintaining connectivity in this landscape. Notably, neither riparian forests nor small fragments are currently targets of PES.

As expected, the maximum distances a species may travel in open habitats had a large influence on functional connectivity (Appendix S3: Fig. S1). Individual core forests often had similar importance for connectivity across flight distances however (Appendix S4: Fig. S1), indicating that differences in movement probability among our species (Fig. 2B) may have been relatively small in comparison to the distances between many isolated patches (0-4614 m, mean of $420 \mathrm{~m}$ ). Dispersal limitation has been shown to differentially structure the community composition of understory insectivores with increasing distance between forest habitats (Moore et al. 2008, Lees and Peres 2009, Ibarra-Macias et al. 2011b). However, at larger distances between patches in fragmented landscapes, individual patch area may be more important for population maintenance (Ferraz et al. 2007).

The contribution of tree plantations to connectivity in our model was small and likely limited by their placement in the landscape in areas with low connectivity value. 


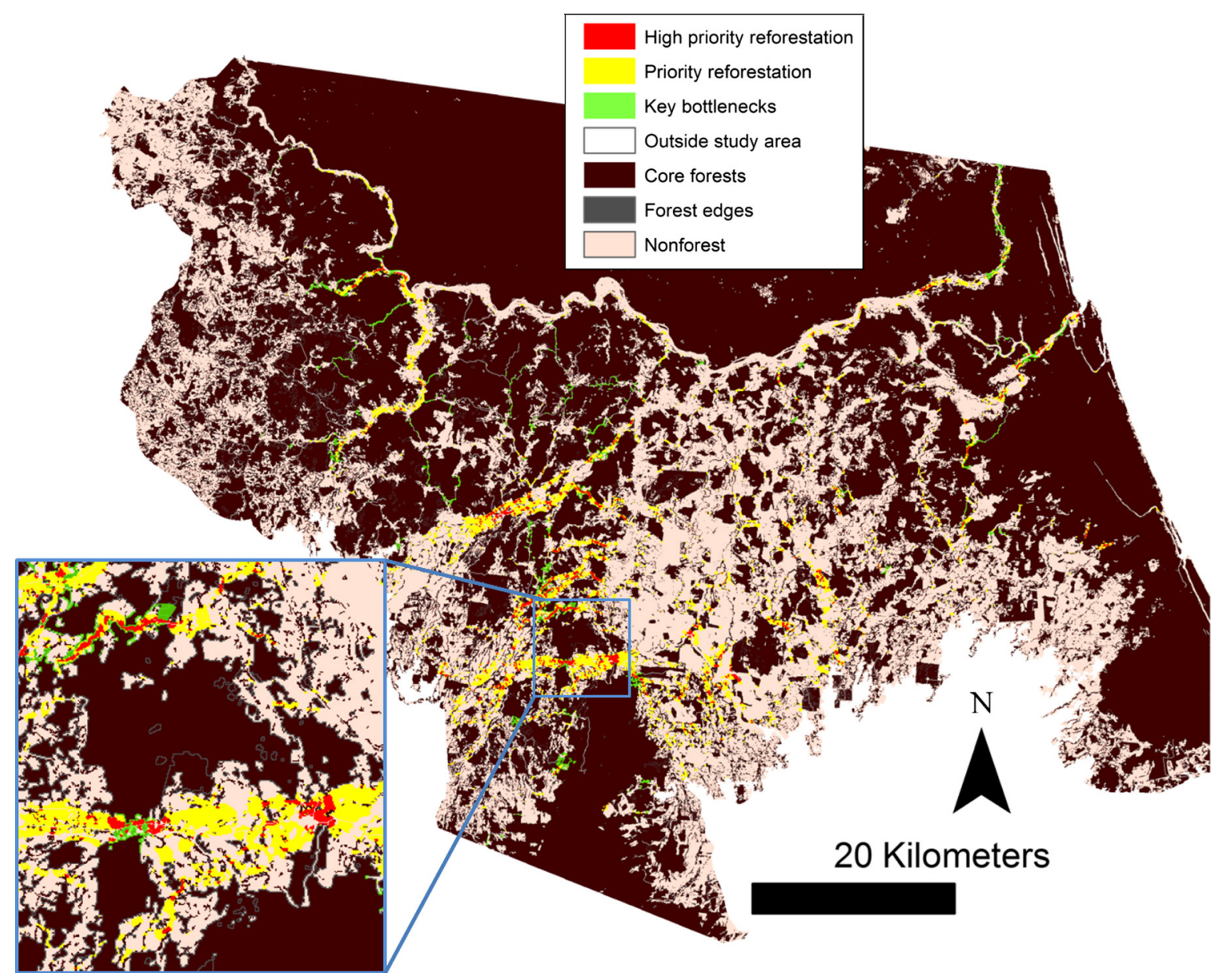

FIG. 7. Map of priority reforestation areas and key bottlenecks to functional connectivity in northeastern Costa Rica. Core forests are shown in dark brown, with core forest edges in dark gray. The inset shows priority reforestation areas and key bottlenecks just northeast of La Selva Biological Station.

Tree plantations were commonly located either adjacent to existing large forests or as isolated stands distant from forest (Fig. 1) rather than bridges between forest patches. The presence of tree plantation patches, despite making up $2 \%$ of the total land area, rarely affected landscape connectivity (Figs. 4 and 6). Some exceptions did exist where five large tree plantation patches were identified as part of the 57 critical bottlenecks important for maintaining current connectivity (Fig. 6). Protecting all tree plantations from clearing over time had little net effect on forest connectivity however. This is mainly due to ad hoc plantation placement and some plantation abandonment, where short-rotation nonnative tree plantations established in the 1980s and 1990s were allowed to revert to secondary forest (S. E. Sesnie, personal communication).

The importance of native and nonnative tree plantations for connectivity for three of our bird species further depended on understory stem density, a factor not included in our graph model (Fig. 3). Understory stem density differed markedly across sites, varying with stand age and management (i.e., cattle density, thinning, fire, and manual clearing; M. E. Fagan, unpublished data). Previous authors have suggested that nonnative tree species have lower value for biodiversity than native species (Lamb 1998, Hartley 2002), but we found that our understory bird species were insensitive to overstory composition. We suggest that dramatic differences among previous studies on biodiversity in tree plantations (Barlow et al. 2007, Fonseca et al. 2009) are partly explained by the presence or absence of native understory vegetation, which can be dense under nonnative overstories (Butler et al. 2008, Fonseca et al. 2009). This observation is in agreement with studies on the presence of remnant native trees in Australian tree plantations (Lindenmayer and Hobbs 2004), structural complexity in agroforests (Nájera and Simonetti 2010), and bird travel in subtropical nonnative pine plantations (Tomasevic and Estades 2008). Restrictions on cattle grazing and silvicultural management for understory vegetation (e.g., after the 3-5-year establishment phase) could increase the connectivity value of tree plantations for understory birds in 
our region. Moreover, techniques to promote understory structure could be further developed through outreach and PES programs already in place.

Further targeting of reforestation in specific areas through PES programs could achieve significant gains in connectivity (a $\sim 2 \%$ increase from reforesting $1 \%$ of the landscape), and help to reconnect the increasingly isolated forested areas at the extreme eastern and western extents of our study region. Although a $2 \%$ gain in connectivity may seem relatively modest, we would expect that reforesting a small area will lead to a small overall shift in the value of the PC connectivity metric, since it includes habitat area (intra-patch connectivity; Saura and Rubio 2010). Targeted reforestation is four times more effective in increasing connectivity than existing reforestation. A point system already exists to prioritize forest protection in certain regions (Daniels et al. 2010), and a similar system could increase payments for tree planting in key connectivity areas to create clusters of reforestation (Drechsler et al. 2010). Including a spatial priority analysis (Fig. 7) could aid evaluation of future reforestation proposals.

Maintaining and restoring connectivity in this rapidly developing frontier region will be challenging. Many key forest bridges and priority reforestation areas are located along roads and in fertile agricultural valleys that are rapidly being converted to high-value crops like pineapple (Fagan et al. 2013). In regions intensively managed for agricultural production, competition between returns from PES subsidies and crop production can limit enrollment by private landowners in PES programs (Phelps et al. 2013). Expansion of urban settlements along the main highway has increasingly isolated Braulio Carrillo from the northern Corridor, and ongoing highway expansion projects may increase this isolation further (ZEE 2013), potentially limiting forest connectivity to underpasses and bridges (Laurance et al. 2009, Lesbarrères and Fahrig 2012). If the central highway is widened near La Selva, protecting and enhancing riparian connectivity at underpasses may prove critical to retaining connectivity between the northern and southern Corridor.

The broad conclusions of this study about functional connectivity and tree plantations are limited by the choice of model taxa and species, by the scale and potential errors in the land cover data, and a reliance on graph models and the literature to estimate connectivity. Although we argue that these four insectivorous species represent other forest-dependent taxa, the landscape connectivity for less mobile forest-dependent animal taxa may be lower and more sensitive to habitat proximity (Prugh et al. 2008, Gardner et al. 2009, Watling et al. 2011). Additionally, sensitivity to edges may influence travel for many taxa (Hansbauer et al. 2008), and edgesensitivity was not included in our graph models. Alternatively, species with greater dispersal abilities and/ or increased ability to use very narrow forest corridors like live fences may not have experienced as large a decline in habitat connectivity. For example, given the large dispersal range of the forest-dependent Ara ambiguus, it is likely that the flagship species for the Corridor region has been more affected by loss of forest area than habitat proximity (Chun 2008). The graph models we used are relatively general however, and could apply to groups with similar dispersal abilities and forest habitat preferences as our study species (Saura et al. 2011).

For the species in this study, we lacked information on their corridor function or their distance-to-avoid-gap, or how far they will travel to avoid a gap of a given size (Knowlton and Graham 2010). In Canada, forest birds that took $50-\mathrm{m}$ flights across open winter fields would travel $500 \mathrm{~m}$ to avoid leaving forest (Bélisle and Desrochers 2002), a 10:1 ratio of open to forest travel. By contrast, none of our species was observed traveling more than 5-10 $\mathrm{m}$ into a completely open field. This difference in gap avoidance behavior between temperate and tropical forest birds is generally known (Stratford and Robinson 2005, Martínez-Ortega et al. 2014), but not well quantified for our species. We selected a high open area to forest resistance ratio (90:1) in our graph model, assuming that all species will travel $2.7 \mathrm{~km}$ of forest in preference to crossing a $30 \mathrm{~m}$ forest gap. Although understory bird species may travel in forest corridors $<10 \mathrm{~m}$ in width (Sieving et al. 2000), species' usage of narrow corridors declines markedly with distance from source forests due to interspecific competition and increasing probability of mortality with travel distance in lower-quality forests (Castellón and Sieving 2006, Lees and Peres 2008). We attempted to represent this potential variation with the narrow- and broadforest sub-scenarios. Our models treated edge and core forest habitat similarly however (resistance of 1), and may overestimate long-distance connectivity for understory insectivores in the narrow-forest sub-scenarios.

Errors in the land cover data were low (Appendix S1: Table S2; Fagan et al. 2013), but classification error could have assigned secondary forest patches within tree plantations and underestimated the contribution of tree plantations to connectivity. The use of the PES property boundaries to assign tree plantations makes this possibility unlikely after 1996, but older tree plantations, planted prior to PES records in the 1980 s, may have transitioned into secondary forest (S. Sesnie, personal communication).

Finally, although we used field data to determine the parameters for our graph models, we did not use direct measurements of animal movement or validate our graph model with field occupancy or genetic data (Zeller et al. 2012). Direct animal movement data are challenging to collect across landscapes and multiple habitat types, especially for dispersing young (Awade and Metzger 2008, Knowlton and Graham 2010). We argue that our playback experiments accurately reflected the relative risks birds faced in different habitat types (Lima and Zollner 1996) and concurred with previous movement studies on our species (e.g., Moore et al. 2008, IbarraMacias et al. 2011a). The detailed understanding of 
movement and breeding ecology required to parameterize connectivity models is lacking for many tropical taxa (Chazdon et al. 2009, Gardner et al. 2009, Knowlton and Graham 2010), but even simple matrix movement data can predict habitat occupancy well for forestdependent birds (Awade and Metzger 2008, Moore et al. 2008, Lees and Peres 2009, Awade et al. 2011).

Collecting field data on population persistence and inbreeding across our landscape is a logical next step in our analysis, although isolated populations of our species and others can take many years to disappear from large fragments (Ferraz et al. 2003, Roberts 2007, Woltmann et al. 2012a). Further work should also extend our connectivity analysis to other taxa, and place this study in a broader regional context. It remains to be seen whether similar results would be obtained in other locations within the Costa Rican corridor system or the larger Mesoamerican Biological Corridor (DeClerck et al. 2010).

Costa Rica has committed to becoming carbon neutral by its bicentennial in 2021 (Lansing et al. 2014), but protecting and increasing tree cover to offset carbon emissions does not always lead to high habitat connectivity (Jantz et al. 2014). Spatial conservation planning and improved habitat management (Brockerhoff et al. 2008, Nájera and Simonetti 2010, Jantz et al. 2014) are needed to make tree plantations and agroforestry a more favorable linkage for species dispersal and movement in fragmented tropical landscapes. Costa Rica has made strides in reducing deforestation rates within the San Juan-La Selva Biological Corridor (Fagan et al. 2013) and raising population numbers of the endangered Great Green Macaw (Chassot and Arias 2013). Our results suggest that more targeted reforestation and forest protection efforts, identified through analyses such as those presented here, are needed to reverse the loss of functional connectivity for understory insectivores in this vital corridor region.

\section{ACKNOWLEDGMENTS}

The authors would like to thank Maria Uriarte, Dustin Rubenstein, Ian Breckheimer, Amanda Wendt, Deborah Visco, Joel Alvarado, Justin Nowakowski, Jennifer Stynoski, Naiara Pinto, Bryan Sigel, Jeffrey Stratford, Jessie Williamson, and Raquel Fagundo for helpful conversations and advice on ornithology and landscape ecology. Field research was made possible by logistical support provided by FUNDECOR, the staff at the Organization for Tropical Studies La Selva Biological Station, and the hospitality of dozens of Costa Rican farmers, who generously allowed M. Fagan to work on their property. We would like to thank Andres Sanchûn, Jose Miranda, Marvin Paniagua, and Mauricio Gaitan for (occasionally life-saving) assistance in the field. We would also like to express our appreciation to Bonnie Tice and Sue Pirkle. This work was funded by National Aeronautics and Space Administration Earth System Science Fellowship NNX10AP49H, NASA Postdoctoral Program Fellowship NNH06CC03B, the ASPRS Ta Liang Memorial Award, The Earth Institute, and the Columbia Institute of Latin American Studies. Finally, the authors wish to thank the two anonymous reviewers for their detailed comments, which markedly improved the original manuscript.

\section{Literature Cited}

Arroyo-Mora, J., S. Svob, M. Kalacska, and R. Chazdon. 2014. Historical patterns of natural forest management in Costa Rica: the good, the bad and the ugly. Forests 5:1777-1797.

Awade, M., and J. P. Metzger. 2008. Using gap-crossing capacity to evaluate functional connectivity of two Atlantic rainforest birds and their response to fragmentation. Austral Ecology 33:863-871.

Awade, M., D. Boscolo, and J. P. Metzger. 2011. Using binary and probabilistic habitat availability indices derived from graph theory to model bird occurrence in fragmented forests. Landscape Ecology 27:185-198.

Barlow, J., et al. 2007. Quantifying the biodiversity value of tropical primary, secondary, and plantation forests. Proceedings of the National Academy of Sciences of the USA 104:18555-18560.

Bélisle, M., and A. Desrochers. 2002. Gap-crossing decisions by forest birds: an empirical basis for parameterizing spatially-explicit, individual-based models. Landscape Ecology 17:219-231.

Blake, J.G., and B. A. Loiselle. 2012. Temporal and Spatial Patterns in Abundance of the Wedge-Billed Woodcreeper (Glyphorynchus spirurus) in Lowland Ecuador. The Wilson Journal of Ornithology 124(3):436-445

Boscolo, D., J. P. Metzger, and J. M. E. Vielliard. 2006. Efficiency of playback for assessing the occurrence of five bird species in Brazilian Atlantic Forest fragments. Anais da Academia Brasileira de Ciências 78:629-644.

Boscolo, D., C. Candia-Gallardo, M. Awade, and J. P. Metzger. 2008. Importance of interhabitat gaps and steppingstones for Lesser Woodcreepers (Xiphorhynchus fuscus) in the Atlantic forest, Brazil. Biotropica 40:273-276.

Brockerhoff, E. G., H. Jactel, J. A. Parrotta, C. P. Quine, and J. Sayer. 2008. Plantation forests and biodiversity: oxymoron or opportunity? Biodiversity and Conservation 17:925-951.

Brooks, T. M., S. L. Pimm, and J. O. Oyugi. 1999. Time lag between deforestation and bird extinction in tropical forest fragments. Conservation Biology 13:1140-1150.

Butler, R., F. Montagnini, and P. Arroyo. 2008. Woody understory plant diversity in pure and mixed native tree plantations at La Selva Biological Station, Costa Rica. Forest Ecology and Management 255:2251-2263.

Butterfield, R. P. 1994. The regional context: land colonization and conservation in La Selva. Pages 299-306 in K. S. B. L. A. McDade, H. A. Hespenheide and G. S. Hartshorn, editors. La Selva: ecology and natural history of a Neotropical rain forest. University of Chicago Press, Chicago, Illinois, USA.

Carnus, J., J. Parrotta, and E. Brockerhoff. 2006. Planted forests and biodiversity. Journal of Forestry 104:65-77.

Castellón, T. D., and K. E. Sieving. 2006. An experimental test of matrix permeability and corridor use by an endemic understory bird. Conservation Biology 20:135-145.

Chassot, O., and G. M. Arias. 2013. Bird conservation across borders in the El Castillo-San Juan-La Selva Biological Corridor, Nicaragua-Costa Rica. Presentation, International Congress of Conservation Biology, Baltimore, Maryland, USA.

Chazdon, R. L. 2008. Beyond deforestation: restoring forests and ecosystem services on degraded lands. Science 320:1458-1460.

Chazdon, R. L., et al. 2009. Beyond reserves: a research agenda for conserving biodiversity in human-modified tropical landscapes. Biotropica 41:142-153.

Chun, S. L. 2008. The utility of digital aerial surveys in censusing Dipteryx panamensis, the key food and nesting tree of the 
endangered great green macaw (Ara ambigua) in Costa Rica Doctoral Dissertation. Duke University. ProQuest.

Cody, M. L. 2000. Antbird guilds in the lowland Caribbean rainforest of southeast Nicaragua. Condor 102:784-794.

Cushman, S. A., K. S. McKelvey, J. Hayden, and M. K. Schwartz. 2006. Gene flow in complex landscapes: testing multiple hypotheses with causal modeling. American Naturalist 168:486-499.

Daniels, A. E., K. Bagstad, V. Esposito, A. Moulaert, and C. M. Rodriguez. 2010. Understanding the impacts of Costa Rica's PES: are we asking the right questions? Ecological Economics 69:2116-2126.

DeClerck, F. A. J., R. Chazdon, K. D. Holl, J. C. Milder, B. Finegan, A. Martinez-Salinas, P. Imbach, L. Canet, and Z. Ramos. 2010. Biodiversity conservation in humanmodified landscapes of Mesoamerica: past, present and future. Biological Conservation 143:2301-2313.

DeFries, R. S., A. Hansen, A. C. Newton, and M. C. Hansen. 2005. Increasing isolation of protected areas in tropical forests over the past twenty years. Ecological Applications 15:19-26.

Drechsler, M., F. Wätzold, K. Johst, and J. F. Shogren. 2010. An agglomeration payment for cost-effective biodiversity conservation in spatially structured landscapes. Resource and Energy Economics 32:261-275.

Fagan, M. E., R. S. DeFries, S. E. Sesnie, J. P. Arroyo, W. Walker, C. Soto, R. L. Chazdon, and A. Sanchun. 2013. Land cover dynamics following a deforestation ban in northern Costa Rica. Environmental Research Letters 8:034017.

Fagan, M. E., R. S. DeFries, S. E. Sesnie, J. P. Arroyo, C. Soto, A. Singh, P. Townsend, and R. L. Chazdon. 2015. Fusing multitemporal Landsat and hyperspectral imagery to monitor tropical tree plantation expansion. Remote Sensing 7:5660-5696.

FAO. 2015. Global forest resources assessment 2015. FAO Forestry Paper No. 1** UN Food and Agriculture Organization, Rome, Italy.

Ferraz, G. G., G. J. Russell, P. C. Stouffer, R. O. Bierregaard, S. L. Pimm, and T. E. Lovejoy. 2003. Rates of species loss from Amazonian forest fragments. Proceedings of the National Academy of Sciences of the USA 100:14069-14073.

Ferraz, G., J. D. Nichols, J. E. Hines, P. C. Stouffer, R. O. Bierregaard, and T. E. Lovejoy. 2007. A large-scale deforestation experiment: effects of patch area and isolation on Amazon birds. Science 315:238-241.

Ferraz, K., M. Micchi de Barros, M. Ferreira de Siqueira, E. Roberto Alexandrino, D. Tomasio, A. Da Luz, and H. Thadeu Zarate do Couto. 2012. Environmental suitability of a highly fragmented and heterogeneous landscape for forest bird species in south-eastern Brazil. Environmental Conservation 39:316-324.

Foltête, J.-C., C. Clauzel, and G. Vuidel. 2012. A software tool dedicated to the modelling of landscape networks. Environmental Modelling \& Software 38:316-327.

Fonseca, C. R., et al. 2009. Towards an ecologically-sustainable forestry in the Atlantic Forest. Biological Conservation 142:1209-1219.

Gardner, T. A., J. Barlow, R. Chazdon, R. M. Ewers, C. A. Harvey, C. A. Peres, and N. S. Sodhi. 2009. Prospects for tropical forest biodiversity in a human-modified world. Ecology Letters 12:561-582.

Gibbs, H. K., A. S. Ruesch, F. Achard, M. K. Clayton, P. Holmgren, N. Ramankutty, and J. A. Foley. 2010. Tropical forests were the primary sources of new agricultural land in the 1980s and 1990s. Proceedings of the National Academy of Sciences of the USA 107:16732-16737.
Hansbauer, M. M., I. Storch, S. Leu, J. P. Nieto-Holguin, R. G. Pimentel, F. Knauer, and J. P. W. Metzger. 2008. Movements of neotropical understory passerines affected by anthropogenic forest edges in the Brazilian Atlantic rainforest. Biological Conservation 141:782-791.

Hartley, M. J. 2002. Rationale and methods for conserving biodiversity in plantation forests. Forest Ecology and Management 155:81-95.

Heller, N. E., and E. S. Zavaleta. 2009. Biodiversity management in the face of climate change: A review of 22 years of recommendations. Biological Conservation $142: 14-32$

Hilty, J. A., W. Z. Lidicker Jr., and A. M. Merenlender. 2006. Corridor ecology: the science and practice of linking landscapes for biodiversity conservation. Island Press, Washington, DC, USA. 323 pp. ISBN 1-55963-096-5

Hilty, J. A., W. Z. Lidicker Jr., and A. M. Merenlender. 2012. Climate and conservation: landscape and seascape science, planning, and action. Island Press.

Holland, M. B. 2012. Mesoamerican biological corridor. Pages 56-66 in J. A. Hilty, C. C. Chester and M. S. Cross, editors. Climate and conservation. Island Press, Washington, D.C., USA.

Ibarra-Macias, A., W. D. Robinson, and M. S. Gaines. $2011 a$. Experimental evaluation of bird movements in a fragmented Neotropical landscape. Biological Conservation 144:703-712.

Ibarra-Macias, A., W. D. Robinson, and M. S. Gaines. $2011 b$. Forest corridors facilitate movement of tropical forest birds after experimental translocations in a fragmented Neotropical landscape in Mexico. Journal of Tropical Ecology 27:547-556.

Jantz, P., S. Goetz, and N. Laporte. 2014. Carbon stock corridors to mitigate climate change and promote biodiversity in the tropics. Nature Climate Change 4:138-142.

Kennedy, C. M., P. P. Marra, W. F. Fagan, and M. C. Neel. 2010. Landscape matrix and species traits mediate responses of Neotropical resident birds to forest fragmentation in Jamaica. Ecological Monographs 80:651-669.

Knowlton, J. L., and C. H. Graham. 2010. Using behavioral landscape ecology to predict species' responses to land-use and climate change. Biological Conservation 143:1342-1354.

Lamb, D. 1998. Large-scale ecological restoration of degraded tropical forest lands: the potential role of timber plantations. Restoration Ecology 6:271-279.

Lansing, D. M., K. Grove, and J. L. Rice. 2015. The neutral state: a genealogy of ecosystem service payments in costa rica. Conservation and Society 13:200-211.

Laurance, S. G. W., and M. S. Gomez. 2005. Clearing width and movements of understory rainforest birds. Biotropica 37:149-152.

Laurance, S. G. W., P. C. Stouffer, and W. E. Laurance. 2004. Effects of road clearings on movement patterns of understory rainforest birds in central Amazonia. Conservation Biology 18:1099-1109.

Laurance, W. F., M. Goosem, and S. G. W. Laurance. 2009. Impacts of roads and linear clearings on tropical forests. Trends in Ecology \& Evolution 24:659-669.

Lees, A. C., and C. A. Peres. 2008. Conservation value of remnant riparian forest corridors of varying quality for Amazonian birds and mammals. Conservation Biology 22:439-449.

Lees, A. C., and C. A. Peres. 2009. Gap-crossing movements predict species occupancy in Amazonian forest fragments. Oikos 118:280-290.

Lesbarrères, D., and L. Fahrig. 2012. Measures to reduce population fragmentation by roads: what has worked and 
how do we know? Trends in Ecology \& Evolution 27:374-380.

Ley Forestal, No. 7575. 1996. Gobierno de la República de Costa Rica, San José, Costa Rica.

Libsch, M. M. 2005. Foraging behavior of foliage-gleaning birds along a rainfall gradient in central Panama: implications for habitat selection and the timing of breeding. University of Illinois at Urbana-Champaign, Champaign, Illinois, USA.

Lima, S. L., and P. A. Zollner. 1996. Towards a behavioral ecology of ecological landscapes. Trends in Ecology \& Evolution 11:131-135.

Lindell, C. A., W. H. Chomentowski, and J. R. Zook. 2004. Characteristics of bird species using forest and agricultural land covers in southern Costa Rica. Biodiversity and Conservation 13:2419-2441.

Lindenmayer, D. B., and R. J. Hobbs. 2004. Fauna conservation in Australian plantation forests - a review. Biological Conservation 119:151-168.

Locatelli, B., C. P. Catterall, P. Imbach, C. Kumar, R. Lasco, E. Marín-Spiotta, B. Mercer, J. S. Powers, N. Schwartz, and M. Uriarte. 2015. Tropical reforestation and climate change: beyond carbon. Restoration Ecology 23:337-343.

Losada-Prado, S. 2009. Home-range and movements of Myrmeciza exsul (Aves: Thamnophilidae) in two fragmented landscapes in Costa Rica: evaluating functional connectivity, Dissertation. CATIE, San José, Costa Rica.

Martínez-Ortega, C., E. S. Santos, and D. Gil. 2014. Speciesspecific differences in relative eye size are related to patterns of edge avoidance in an Amazonian rainforest bird community. Ecology and Evolution 4:3736-3745.

Mazaris, A. D., A. D. Papanikolaou, M. Barbet-Massin, A. S. Kallimanis, F. Jiguet, D. S. Schmeller, and J. D. Pantis. 2013. Evaluating the connectivity of a protected areas' network under the prism of global change: the efficiency of the European Natura 2000 network for four birds of prey. PLoS ONE 8:e59640.

McRae, B. H., and P. Beier. 2007. Circuit theory predicts gene flow in plant and animal populations. Proceedings of the National Academy of Sciences of the USA 104:19885-19890.

McRae, B., and D. Kavanagh. 2011. Linkage Mapper Connectivity Analysis Software, Seattle, Washington, USA.

McRae, B. H., B. G. Dickson, T. H. Keitt, and V. B. Shah. 2008. Using circuit theory to model connectivity in ecology, evolution, and conservation. Ecology 89:2712-2724.

McRae, B. H., S. A. Hall, P. Beier, and D. M. Theobald. 2012. Where to restore ecological connectivity? Detecting barriers and quantifying restoration benefits. PLoS ONE 7:e52604

Meyfroidt, P., and E. F. Lambin. 2008. The causes of the reforestation in Vietnam. Land Use Policy 25:182-197.

Moore, R. P., W. D. Robinson, I. J. Lovette, and T. R. Robinson. 2008. Experimental evidence for extreme dispersal limitation in tropical forest birds. Ecology Letters 11:960-968.

Morse, W. C., J. L. Schedlbauer, S. E. Sesnie, B. Finegan, C. A. Harvey, S. J. Hollenhorst, K. L. Kavanagh, D. Stoian, and J. D. Wulfhorst. 2009. Consequences of environmental service payments for forest retention and recruitment in a Costa Rican biological corridor. Ecology and Society 14:23.

Naidoo, R., A. Balmford, P. J. Ferraro, S. Polasky, T. H. Ricketts, and M. Rouget. 2006. Integrating economic costs into conservation planning. Trends in Ecology \& Evolution 21:681-687.

Nájera, A., and J. A. Simonetti. 2010. Enhancing avifauna in commercial plantations. Conservation Biology 24: 319-324.
Newbold, T., J. P. W. Scharlemann, S. H. M. Butchart, C. H. Sekercioğlu, R. Alkemade, H. Booth, and D. W. Purves. 2013. Ecological traits affect the response of tropical forest bird species to land-use intensity. Proceedings of the Royal Society B 280:20122131.

Nogués, S., and A. Cabarga-Varona. 2014. Modelling land use changes for landscape connectivity: the role of plantation forestry and highways. Journal for Nature Conservation 22:504-515.

Pagiola, S. 2008. Payments for environmental services in Costa Rica. Ecological Economics 65:712-724.

Phelps, J., L. R. Carrasco, E. L. Webb, L. P. Koh, and U. Pascual. 2013. Agricultural intensification escalates future conservation costs. Proceedings of the National Academy of Sciences of the USA 110:7601-7606.

Porras, I., D. N. Barton, M. Miranda, and A. ChacónCascante. 2013. Learning from 20 years of payments for ecosystem services in Costa Rica. International Institute for Environment and Development, London, UK.

Prevedello, J. A., and M. V. Vieira. 2009. Does the type of matrix matter? A quantitative review of the evidence. Biodiversity and Conservation 19:1205-1223.

Prugh, L. R., K. E. Hodges, A. R. E. Sinclair, and J. S. Brashares. 2008. Effect of habitat area and isolation on fragmented animal populations. Proceedings of the National Academy of Sciences 105:20770-20775.

R Development Core Team. 2012. R: A language and environment for statistical computing. R Foundation for Statistical Computing, Vienna, Austria. http://www. R-project.org/

Read, J., J. Denslow, and S. Guzman. 2001. Documenting land cover history of a humid tropical environment in northeastern Costa Rica using time-series remotely sensed data. Pages 69-89 in A. C. Millington, S. J. Walsh and P. E. Osborne, editors. GIS and remote sensing applications in biogeography. Kluwer Academic Publishers, Boston, Massachusetts, USA.

Robalino, J., and A. Pfaff. 2013. Ecopayments and deforestation in Costa Rica: a nationwide analysis of PSA's initial years. Land Economics 89:432-448.

Roberts, D. L. 2007. Effects of tropical forest fragmentation on ecology and conservation of migrant and resident birds in lowland Costa Rica. Dissertation. University of Idaho, Moscow, Idaho, USA.

Robinson, W. D., J. D. Brawn, and S. K. Robinson. 2000. Forest bird community structure in central Panama: influence of spatial scale and biogeography. Ecological Monographs 70:209-235.

Roper, J. J. 1996. Nest predation and its importance, the western Slaty Antshrike (Thamnophilus atrinucha): the problem, experiments and simulations. University of Pennsylvania, Philadelphia, Pennsylvania, USA.

Saccheri, I., M. Kuussaari, M. Kankare, P. Vikman, W. Fortelius, and I. Hanski. 1998. Inbreeding and extinction in a butterfly metapopulation. Nature 392:491-494.

Sader, S. A., and A. T. Joyce. 1988. Deforestation rates and trends in Costa Rica, 1940 to 1983. Biotropica 20(1): $11-19$.

Sánchez-Azofeifa, G. A., C. Quesada-Mateo, P. GonzalezQuesada, S. Dayanandan, and K. S. Bawa. 1999. Protected areas and conservation of biodiversity in the tropics. Conservation Biology 13:407-411. doi: 10.1046/j.1523-1739. 1999.013002407.x

Sánchez-Azofeifa, G. A., G. C. Daily, A. S. P. Pfaff, and C. Busch. 2003. Integrity and isolation of Costa Rica's national parks and biological reserves: examining the dynamics of land-cover change. Biological Conservation 109:123-135. 
Sánchez-Azofeifa, G. A., K. L. Castro-Esau, W. A. Kurz, and A. Joyce. 2009. Monitoring carbon stocks in the tropics and the remote sensing operational limitations: from local to regional projects. Ecological Applications 19:480-494.

Sandel, B., and J. C. Svenning. 2013. Human impacts drive a global topographic signature in tree cover. Nature Communications 4 .

Saura, S., and L. Pascual-Hortal. 2007. A new habitat availability index to integrate connectivity in landscape conservation planning: comparison with existing indices and application to a case study. Landscape and Urban Planning 83:91-103.

Saura, S., and L. Rubio. 2010. A common currency for the different ways in which patches and links can contribute to habitat availability and connectivity in the landscape. Ecography 33:523-537.

Saura, S., C. Estreguil, C. Mouton, and M. Rodríguez-Freire. 2011. Network analysis to assess landscape connectivity trends: application to European forests (1990-2000). Ecological Indicators 11:407-416.

Seiferling, I. S., R. Proulx, P. R. Peres-Neto, L. Fahrig, and C. Messier. 2012. Measuring protected-area isolation and correlations of isolation with land-use intensity and protection status. Conservation Biology 26:610-618.

Sekercioglu, C. H., and N. S. Sodhi. 2007. Conservation biology: predicting birds' responses to forest fragmentation. Current Biology 17:R838-R840.

Sekercioglu, C. H., P. R. Ehrlich, G. C. Daily, D. Aygen, D. Goehring, and R. F. Sandi. 2002. Disappearance of insectivorous birds from tropical forest fragments. Proceedings of the National Academy of Sciences of the USA 99:263-267.

Sieving, K. E., M. F. Willson, and T. L. De Santo. 2000. Defining corridor functions for endemic birds in fragmented south-temperate rainforest. Conservation Biology 14: $1120-1132$.

Sigel, B. J., W. D. Robinson, and T. W. Sherry. 2010. Comparing bird community responses to forest fragmentation in two lowland Central American reserves. Biological Conservation 143:340-350.

Sterling, S., and A. Ducharne. 2008. Comprehensive data set of global land cover change for land surface model applications. Global Biogeochemical Cycles, 22:GB3017, doi:10.1029/2007GB002959.

Stiles, F. G., A. F. Skutch, and D. Gardner. 1989. A guide to the birds of Costa Rica. Comstock Publishing Associates, Ithaca, New York, USA.

Stork, N. E., J. A. Coddington, R. K. Colwell, R. L. Chazdon, C. W. Dick, C. A. Peres, S. Sloan, and K. Willis. 2009. Vulnerability and resilience of tropical forest species to land-use change. Conservation Biology 23:1438-1447.

Stratford, J. A., and W. D. Robinson. 2005. Gulliver travels to the fragmented tropics: geographic variation in mechanisms of avian extinction. Frontiers in Ecology and the Environment 3:91-98.
Tarwater, C. E., and J. D. Brawn. 2010. Family living in a Neotropical bird: variation in timing of dispersal and higher survival for delayed dispersers. Animal Behaviour 80:535-542.

Taylor, P. D., L. Fahrig, K. Henein, and G. Merriam. 1993. Connectivity is a vital element of landscape structure. Oikos 68:571-573.

Tischendorf, L., and L. Fahrig. 2000. On the usage and measurement connectivity. Oikos 90:7-19.

Tomasevic, J. A., and C. F. Estades. 2008. Effects of the structure of pine plantations on their "softness" as barriers for ground-dwelling forest birds in south-central Chile. Forest Ecology and Management 255:810-816.

Tubelis, D. P., D. B. Lindenmayer, and A. Cowling. 2007. Bird populations in native forest patches in south-eastern Australia: the roles of patch width, matrix type (age) and matrix use. Landscape Ecology 22:1045-1058.

Urban, D., and T. Keitt. 2001. Landscape connectivity: a graph-theoretic perspective. Ecology 82:1205-1218.

Van Bael, S. A., P. Bichier, I. Ochoa, and R. Greenberg. 2007. Bird diversity in cacao farms and forest fragments of western Panama. Biodiversity and Conservation 16:2245-2256.

Van Houtan, K. S., S. L. Pimm, J. M. Halley, R. O. Bierregaard, and T. E. Lovejoy. 2007. Dispersal of Amazonian birds in continuous and fragmented forest. Ecology Letters 10:219-229.

Watling, J. I., A. J. Nowakowski, M. A. Donnelly, and J. L. Orrock. 2011. Meta-analysis reveals the importance of matrix composition for animals in fragmented habitat. Global Ecology and Biogeography 20:209-217.

Watson, V., S. Cervantes, C. Castro, L. Mora, M. Solis, I. T. Porras, and B. Cornejo. 1998. Making space for better forestry: policy that works for forests and people. Centro Cientifico Tropical and the International Institute for Environment and Development, San José, Costa Rica and London, UK.

Woltmann, S., B. R. Kreiser, and T. W. Sherry. 2012a. Finescale genetic population structure of an understory rainforest bird in Costa Rica. Conservation Genetics 13:925-935.

Woltmann, S., T. W. Sherry, and B. R. Kreiser. 2012b. A genetic approach to estimating natal dispersal distances and self-recruitment in resident rainforest birds. Journal of Avian Biology 43:33-42.

Woltmann, S., R. S. Terrill, M. J. Miller, and M. L. Brady. 2013. Chestnut-backed Antbird (Myrmeciza exsul). http:// neotropical.birds.cornell.edu/portal/species/overview?p_p_ spp $=393811$.

ZEE. 2013. Zona Económica Especial: Zona Norte de Costa Rica. http://www.zeezn.com/index.php?option=com_content $\&$ view $=$ article \&id $=65 \&$ Itemid $=118$.

Zeller, K. A., K. McGarigal, and A. R. Whiteley. 2012. Estimating landscape resistance to movement: a review. Landscape Ecology 27:777-797.

Zurita, G. A., and M. I. Bellocq. 2010. Spatial patterns of bird community similarity: bird responses to landscape composition and configuration in the Atlantic forest. Landscape Ecology 25:147-158.

\section{SUPPORTING INFORMATION}

Additional supporting information may be found in the online version of this article at http://onlinelibrary.wiley.com/ doi/10.1890/14-2188/suppinfo 